\title{
Zur Theorie des Staatskapitalismus - Probleme von Theorie und Geschichte in Theorien der Úbergangsgesellschaft*
}

\author{
Werner Olle
}

Gegenwärtig wird in der sozialistischen Bewegung einiger westeuropäischer Länder das sichtbar gewordene Dilemma einer (als Kritik intendierten) Theorie der Ubergangsgesellschaften thematisiert, wobei von unterschiedlichen Ansätzen her nach Interpretationen und Lösungen gesucht wird.

Das Dilemma dieser Kritik sei im Grunde ein Dilemma der Kritiker, weil diese Kritik aufgehört habe, Kritik in praktischer Absicht zu sein. Jirí Kosta kritisiert diese fehlende praktische Intention:

„,Algemeine Hinweise auf die Notwendigkeir politischer Entscheidungen und der Schaffung politischen Bewußtseins lösen nicht die Probleme der Planungspraxis. " (1)

Der sozialistischen Bewegung in den noch kapitalistischen Ländern kann es bei der Analyse der Entwicklung der Übergangsgesellschaften allerdings nicht um die Lösung von Problemen der „Planungspraxis“ gehen, sondern höchstens darum, die Erfahrung der realen Schwierigkeiten der sozialistischen Transformation für die eigene gesellschaftliche Praxis aufzunehmen; ,praktische“ Absicht also zutreffender im Sinne von „emanzipatorischer" Absicht. Die theoretische Analyse müßte sich dann allerdings - so folgert Helmut Fleischer - anders als bislang artikulieren, nämlich:

„, in praktischen Termini als Ausdruck eines Interesses, welches der Theorie-Form nur als einem Moment einer Praxisform gilt." (2)

In der Interpretation von Rossana Rossanda wird das Dilemma im Verhältnis der westlichen sozialistischen Bewegung $\mathrm{zu}$ den Übergangsgesellschaften wesentlich psychologistisch gefaßt: als ,Verhältnis der Haßliebe“", als lächerlicher „Hoffnungsund Enttäuschungszusammenhang", als „Exorzismus", als ,andauernder Ehe-

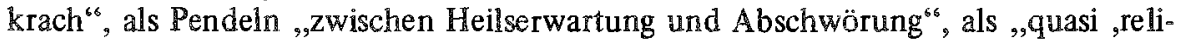

* Dieser Aufsatz ist eine unwesentlich gekürzte Fassung einer Diplomarbeit, die am Fachbereich 15 der Freien Universität Berlin unter dem Titel , Zum Verhältnis von Theorie und Geschichte in Theorien der Übergangsgesellschaft am Beispiel der Theorie des Staatskapitalismus"im Mai 1973 eingereicht wurde. An der Diskussion über diese Arbeit waren insbesondere Elmar Altvater, Renate Damus, Jürgen Hoffmann und Rainer Single beteiligt.

1) Jï Kosta, Jan Meyer, Sibylle Weber, Warenproduktion im Sozialismus. Überlegungen zur Theorie von Marx und zur Praxis in Osteuropa, Frankfurt 1973, S. 136

2) Helmut Fleischer, Normativistisches und materialistisches Verständnis der sozialistischen Transformation, in: Praxis, Revue philosophique, Edition internationale, Nr. 3-4, Zagreb 1972, S. 277 
giöses ${ }^{6}$ " Verhältnis (3) etc. . Dieses Psychogramm mag eine zutreffende Charakterisierung der Identitätsstrukturen von Teilen der Kritiker sein, aber Theoriebildung, und folglich auch ihr aktuelles Dilemma, läßt sich nicht darauf reduzieren.

Sicherlich wird jede Theoriebildung auch durch die Intentionen der Theorieproduzenten selbst bestimmt. Trotzki weist etwa in seiner Kritik der Einschätzung der Entwicklung der Sowjetunion durch den "Leninbund ${ }^{66}$ darauf hin, daß dessen theoretische Position nur, ,durch seine, mindestens unbegründeten Ansprüche auf die Rolle einer zweiten Partei" vollständig erklärbar wird, und er führt aus:

„Es existieren zux Zeit genügend, linke ${ }^{6}$ Gruppen und Grüppchen, die auf ein und demselben Platz trampeln; während sie ihre Selbständigkeit verteidigen, beschuldigen sie sich gegenseitig, die anderen gingen nicht weit genug; die darauf stolz sind, mit den anderen hundertprozentig nicht einverstanden zu sein; von Zeit zu Zeit ein Blättchen herausgeben und Befriedigung finden in dieser illusorischen Existenz ohne Boden unter den Füßen, ohne klaren Standpunkt und ohne Perspektive. Da diese Gruppen oder richtiger Spitzen, die eigene Schwäche fuhlen, fürchten sie am meisten, unter jemands ,Einfluß ${ }^{66}$ zu geraten, oder sich mit jemand solidarisch erklären zu müssen, - denn wo Uleibt dann die süße Selbständigkeit in der Größe von 64 Kubikmetern, wie es für ein Redaktionszimmer nötig ist? " (4)

Diese Funktion eines, ,mindestens unbegründeten" Parteianspruchs für die Theoriebildung ließe sich auch gegenwärtig in der sozialistischen Bewegung der Bundesrepublik etwa an der Gruppe „Neues Rotes Forum" rekonstruieren. Denn diese Gruppierung war noch 1971 der Ansicht: „Die Frage, ob in der Sowjetunion eine neue Bourgeoisie die Herrschaft ausübt, wird nicht entschieden. Dazu bedürfte es anderer Analysen als der bisher vorhandenen", und sie warnte vor der Gefahr, „Behauptungen aufzustellen, die wir noch nicht beweisen können“(5). Ohne "andere Analysen ${ }^{6,}$, dafür aber durch die anstehende Vereinigung mit anderen Gruppen, wird heute behauptet, daß in der Sowjetunion ,die Bourgeoisie nach einer jahrzehntelangen Herrschaft der Arbeiterklasse wieder an die Macht gekommen ist" (6).

Diese Interpretationen, die das Dilemma einer theoretischen Analyse der Übergangsgesellschaften wesentlich den Theorieproduzenten - ihrer mangelnden praktischen Intention und politischen Souveränität bzw. der bloßen Instrumentalisierung der theoretischen Analyse zur Aufrechterhaltung jener, ,süßen Selbständigkeit ${ }^{6}$ - anlasten, sprechen zweifellos erklärende Faktoren an, wenn es auch insgesamt zu bestreiten ist, daß es sich bei dem Dilemma aktueller Theoriebildung ausschließlich um ein Dilemma der Kritiker handelt.

Mir scheint, daß diese Interpretationen - wenn sie als ausschließliche Erklärungen figurieren - sogar eine spezifische Schwäche beinhalten, da sie die Schlußfolge-

3) Eine nicht vollständige Auswahl aus dem Artikel von Rossana Rossanda, Die sozialistischen Länder: Ein Dilemma der westeuropäischen Linken, in: Kursbuch 30, Westberlin 1973

4) Leo Trotzi, Die Verteidigung der Sowjetrepublik und die Opposition, Berlin 1929 , S. 38 in.

5) Joscha Schmierer, Kapitalistischer und sozialistischer Weg in der Úbergangsperiode zum Sozialismus, in: Neues Rotes Forum Nr. 3, Heidelberg 1971, S. 46

6) Materialien zum Problem der Übergangsperiode zum Sozialismus und zum Klassencha-

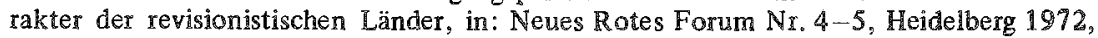
S. 13 
rung nahe legen, daß es sich dabei um ein nur temporär bedingtes Problem handle, dessen "Lösung" sich demnach auch auf die Kritik der Theorieformen aktueller Degenerationserscheinungen einer Intellek tuellenbewegung beschränken kann.

$\mathbb{Z}$ umindest muß gefragt werden, ob dieses Dilemma aktueller Theoriebildung nicht auch zugleich ein Dilemma der Kritik ist: der verwendeten Kategorien und der Methode der Kritik. Die Notwendigkeit dieser Fragestellung wird etwa aus folgender Aussage eines Kritikers ersichtlich:

„Für die Kommunisten stellt sich die Aufgabe, durch konkrete Analysen und präzise Begriffe (Revisionismus, Bourgeoisie neuen Typs etc.) die sowjetische Wirklichkeit zu analysieren, um der russischen Arbeiterklasse den Feind zu zeigen und den Schleier der revolutionären Phrasen der sowjetischen Bourgeoisie zu zerreißen." (7)

Diese Aussage ist nicht nur symptomatisch wegen der einen Teil der Kritiker kennzeichnenden Mentalität des ,der-Arbeiterklasse-zeigen-wollen ${ }^{66}$, die hier omnipotente Ausmaße annimmt, sondern auch deswegen, weil sie einen bezeichnenden Widerspruch enthält. Denn hier wird in entlarvender Offenheit ein methodisches Prinzip ausgegeben, das expliziert, , durch konkrete Analysen und präzise Begriffe " zu einer theoretischen Erfassung der gesellschaftlichen Wirklichkeit der Übergangsgesellschaften zu gelangen. Diese postulierte Parallelität einer Aneignung des Konkreten und einer theoretischen Abstraktion destruiert eine wissenschaftliche Theoriebildung, die nur als Einheit von Konkretem und Abstraktem denkbar ist, als , Reproduktion des Konkreten im Weg des Denkens“ (8). In der Konsequenz läßt diese Parallelität eine Trennung der beiden Momente zu, sei es als bloß konstatierende Deskription einer Faktizität, sei es als theoretische Konstruktion außerhalb einer Aneignung des Konkreten, sei es in verdeckteren Formen, in denen Theorie bzw. Empirie nur post festum einer bereits gesetzten Empirie bzw. Theorie unterlegt wird. Diese Parallelität in Form einer vollzogenen Trennung manifestiert sich in dem obigen Zitat darin, daß die konkrete Analyse als noch ausstehende Aufgabe definiert wird, zugleich aber von der Existenz einer, sowjetischen Bourgeoisie" ausgegangen wird.

Hier drängen sich zwei Schlußfolgerungen auf.

Erstens: es ließe sich - ausgehend von dem Zusammenhang ,konkre te Analysen " $\%$,präzise Begriffe" - folgern, daß, solange diese konkreten Analysen nicht integraler Bestandteil einer Theoriebildung sind, die produzierten Begriffe auch in dem einzig möglichen Sinne, ,ein geistig Konkretes zu reproduzieren“ (9), nicht „präzise“ sein können. Die so produzierten Begriffe signalisieren nur eine ,Dogmatisierung der revolutionären Theorie ${ }^{66}$, die, weil abstrakt, zur ,,sozialistischen Moral ${ }^{6}$ verkommt (10).

7) „Philipp Neumann", Welcher Klassenstandpunkt bestimmt Vargas Analyse?, in: Kursbuch 23, Westberlin 1971, S. $77 \mathrm{f}$.

8) Karl Marx, Grundrisse der Kritik der politischen Okonomie, Frankfurt 1970, \$. 22

9) ebda.

10) Bernd Rabehl, Eine Reise in die DDR. Gespräche und Notizen, in: Kursbuch 30, a. a. 0 ., S. 48 f. Die Warnung Rabehls, daß ,der abstrakte Anti-Revisionismus ... zu Positionen (komme), die vom Antikommunismus kaum mehr unterscheiळbar sind ${ }^{66}$, bestätigt sich gerade an dieser Ausgabe des Kursbuches in dem Artikel von Güter Maschke (, Cubani- 
Zweitens: es hieße aber, sich nur auf die Erscheinungsform dieser Theoriebildung beschränken, woll te man hierin ein bloßes Problem der Vermittlung von Theorie und Empirie sehen, das beliebig korrigierbar ist. Diese mangelnde Vermittlung (11) verweist vielmehr auf eine bestimmte Auffassung von gesellschaftlicher Wirklichkeit, eine bestimmte Konzeption yon Geschichte, deren Resultat sie ist; eine Konzeption von Geschichte, die es erlaubt, ja begründet, Theorie außerhalb einer Aneignung des Konkreten zu konstituieren:

,Nicht der Mangel an Vermittlung, sondern die Auffassung des gesellschaftlichen Seins selbst kennzeichnet den vulgären Ansatz." (12)

Aber kann man sich darauf beschränken, nur die bestimmte Methode einer Kritik zu unterziehen? Ich habe weiter oben bewubt die Aussage eines Kritikers aus der westdeutschen Studentenbewegung zitiert, weil sie ein interessantes Phänomen zeigt: eine fast gleichlautende Explizierung der Methode, wie sie auch etwa Charles Bettelheim gegeben hat, wenn er beansprucht,

„... die zur Analyse der Gesellschaftsformationen im Übergang zwischen Kapitalismus und Sozialismus notwendigen Begriffe zu schaffen oder zu präzisieren ... ", obgleich ,die Anwendung der Begriffe in einer konkreten Analyse ... nur in Umarissen geleistet (ist)." (13)

Das Interessante besteht darin, daß Bet telheim als Protagonist einer an ti-historizistischen, strukturalen Konzeption der Kritik der politischen Ökonomie bewußt eine Methode formuliert, deren, ,Voraussetzung und theoretischer Kern ... die Evakuierung der Geschichte, ihre Erniedrigung zu einer Dienerin der Struktur, des Systems und der Wissenschaft" ${ }^{6}(14)$ ist; eine Enthistorisierung der Theorie, die sich in den Aussagen und Analysen etwa aus der westdeutschen Studentenbewegung zwar auch darstellt, ohne daß hier allerdings eine bewußt strukturalistische Konzeption der Grund sein dürfte. Von daher entsteht nun die Notwendigkeit, auch über eine rein methodische Kritik hinauszugehen, da dieser Ansatz seinerseits die Gefahr enthält, die kritisierte bestimmte Methode wiederum einer Art von Beliebigkeit zu überlassen, so als ob etwa die Enthistorisierung der theoretischen Analyse der Entwicklung der Übergangsgesellschaften ein ausschließliches Problem der „Strukturalisten“" sei (15).

scher Taschenkalender ${ }^{65}$ ), dessen Assoziationskette „Hunger-Angst-DesarganisationTerror-Lüge" für den Antikommunismus zumindest funktionalisierbar wird. Der "Unternehmerbrief des Deutschen Industrie-Instituts" vom 1.3.1973 hat sich daher auch Maschkes hätschelnd angenommen.

11) Bei einem Großteil der westdeutschen Literatur zu diesem Thema handelt es sich nicht nur um eine mangelnde Vermittlung von Theorie und Empirie, hier konstituiert sich Empirie als Ulbricht-, Honecker-etc. -Zitatensammlung, die in den diversen Nachweisen einer Restauration des Kapitalismus immer wieder umgruppiert wird.

12) Karel Kosik, Gesellschaftliches Sein und ökonomische Kategorien, in: Folgen einer Theorie. Essays über, Das Kapital' von Karl Marx, Frankfurt 1967, S. 101

13) Charles Bettelheim, Ökonomischer Kalkïl und Eigentumsformen, Westberlin 1970, S.7

14) K. Nair, Charles Bettelheims Umwälzung der Wissenschaft, in: Kritik der politischen Ökonomie Nr. 1, Westberlin 1973, S. 22

15) Das scheint mir auch der spezifische Mangel der beiden, ansonsten ausgezeichneten Kriti- 
Diese Abgrenzung gegenüber anderen Interpretationen ermöglicht es, eigene Fragestellungen zu präzisieren. Wenn das, was als Dilemma der theoretischen Analy. se der Ubergangsgesellschaften bezeichnet wird, einerseits seinem Inhalt nach als Enthistorisierung von Theorie gefaßt werden kann, andererseits abgelehnt werden muß, daß es sich dabei ausschließlich um Theorie-Formen handelt, die erst aus jüngsten Degenerationserscheinungen einer Intellektuellenbewegung bzw. aus einem bestimmten wissenschaftstheoretischen Ansatz resultieren, so wirft das natïrlich die Frage nach einer theoretischen Erfassung der Wirklichkeit der Übergangsgesellschaften durch die sozialistische Bewegung in den noch kapitalistischen Ländern insgesamt als Problem auf.

Diese Fragestellung scheint mir aus verschiedenen Gründen die aktuell notwendige zu sein:

zum einen, weil in ihr das Problem als ein gemeinsames Problem der sozialistischen Bewegung formuliert wird;

zum zweiten, weil mit ihr als Negation intendiert ist, gegenüber einem ,falschen" Objektivismus eine "Demarkationslinie" zu ziehen, d.h. gegenüber jenen Versuchen, die die so offensichtlichen Schwierigkeiten einer theoretischen Analyse der Ubergangsgesellschaften in verkehrter Form objektivieren, indem sie das Dilemma, die Enthistorisierung der Theorie, zur Methode erheben;

zum dritten, veil aus ihr langfristig eine positive Präzisierung der Möglichkeiten einer theoretischen Analyse der Übergangsgesellschaften durch die westliche sozialistische Bewegung resultieren kann, die dann eventuell auch eine Umorientierung aktueller theoretischer Arbeiten begründet.

An diesem globalen, praxisbezogenen Kontext orientieren sich die folgenden Überlegungen, obwohl sie sich selbst notwendig auf einen Teilaspekt beschränken. Wenn das sogenannte Dilemma aktueller Theoriebildung im Verhältnis von Theorie und Geschichte in Form einer Enthistorisierung der Theorie begründet ist, andererseits aber nicht erst seit heute existiert, so verweist das auf folgende Fragestellungen: Wie sind denn unsere Theorien überhaupt entstanden, mit denen wir die Entwicklung der Übergangsgesellschaften heute kritisieren? Sind die von uns verwendeten Kategorien (etwa Bürokratie, Technokratie, Staatskapitalismus etc.) tatsächlich Widerspiegelung einer Wirklichkeit der Übergangsgesellschaften oder nicht vielmehr die unserer eigenen, die wir auf die der Übergangsgesellschaften übertragen?

Diese Fragestellungen, die, unter einem historisch-genetischen Aspekt auf das Verhältnis unserer. Theoriebildung zur geschichtlichen Wirklichkeit der Übergangsgesellschaften abzielen, sollen im folgenden an einer Theorievariante - der Theorie des Staatskapitalismus - angegangen werden, wobei ich mich darauf beschränken muß, zum einen die spezifische historische Bedingtheit der Genesis überhaupt, zum anderen die Bedingungen einer Übertragung der Theorie des Staatskapitalismus auf die Übergangsgesellschaften am Beispiel der russischen Revolution zu zeigen.

In einem zweiten Schritt sollen dann unterschiedliche Varianten dargestellt werden, die sich als Nachweis der Existenz eines Staatskapitalismus in den Ubergangsgesellschaften definieren. Deren unterschiedliche Begründungsmuster dienen

ken der Theorie Bettelheims zu sein, die K. Nair, a. a. O., und J. L. Dallemagne, Charles Bettelheim oder die Identität der Gegensätze, ebd. geliefert haben. 
lediglich als Beleg eines gemeinsamen Problems, der Schwierigkeit einer historischmaterialistischen Analyse der Übergangsgesellschaften, die nicht kaschiert werden darf. Sie dienen nicht als diffamierende ,Sammelabrechnung“, die Theoriegeschichte als bloße Ideengeschichte begreift, was es ja erst erlaubt, die unterschiedlichsten Vertreter einer bestimmten Theorie in den gemeinsamen Sack einer theoretischen „Tradition ${ }^{6 s}$ zu stecken, die dann aber diese nicht mehr mit der historischen Singularität jeder einzelnen Variante zu vermitteln weiß (16).

Sowohl aus dem globalen Charakter der Fragestellung wie der praktischen Intention ergibt sich von selbst, daß die folgenden Überlegungen lediglich eine erste Annäherung an das Problem sein können, die durch weitere kollektive Arbeiten und Diskussionen weiterverfolgt werden sollten.

\section{Genesis und Anwendungsbereich der Theorie des Staatskapitalismus}

\subsection{Die Besonderheit der Theorie des Staatskapitalismus und ihre allgemeine Pro. blematik}

Die folgende Beschränkung auf die Theorie des Staatskapitalismus intendiert keineswegs die Immunisierung anderer Varianten einer Theorie der Übergangsgesellschaft (17) gegenüber analogen Fragestellungen (18). Diese Beschränkung hat vielmehr exemplarischen Charakter, die aufgrund der Besonderheit der Theorie des Staatskapitalismus gerechtfertigt erscheint. Denn der Begriff des Staatskapitalismus findet heute Anwendung auf unterschiedliche Gesellschaftsformationen: sowohl die Entwicklung der monopolkapitalistischen, wie der unterentwickelten Länder, wie auch die der Übergangsgesellschaften wird im Sinne einer staatskapitalistischen Entwicklung interpretiert.

16) Beispiele dieser ,Sammelabrechnung" finden sich etwa bei Maurice Dobb, Die Oktoberrevolution und ein halbes Jahrhundert, in: Bettelheim/Dobb/Foa/Huberman/Robinson/Mandel/Sweezy u. a., Zur Kritik der Sowjetökonomie, Westberlin 1969, S. 143; und Ernest Mandel, Die Widersprüchlichkeit der ,Theorie des Staatskapitalismus", in: Permanente Revolution Nr. 3, Westberlin 1972, S. 49 und S. 68 f.

17) Der Begriff der ,Übergangsgesellschaft" vom Kapitalismus zum Sozialismus braucht aufgrund der intensiven Diskussion der letzten Jahre zu diesem Thema nicht mehr expliziert werden. Vgl für viele andere z. B. Ernest Mandel, Politische Ökonomie der Übergangsperiode, in: Permanente Revolution Materialien Nr. 1, Westberlin 1972, S. 3 ff. und Charles Bettelheim, Ökonomischer Kalkül ..., a. a. 0., insb. S. $67 \mathrm{ff}$. und S. $118 \mathrm{ff}$.

18) Sie gelten natürlich auch für unsere Analyse des chinesischen Transformationsprozesses. Selbstkritisch wäre hier anzumerken, daß unsere Intention, aus der konkreten Entwicklung der VR China u. a. Kriterien für die Kritik eines „orthodoxen“ Bürokratie-Begriffs und gleichzeitig einen Beitrag zu dessen Differenzierung zu leisten, sich einerseits durchaus in die hier entwickelten Fragestellungen einordnet, andererseits diese kritische Fragestellung in dem Maße aufgegeben wurde, wie wir lediglich eine differenziertere Begrifflichkeit vorgeschlagen haben. Vgl. Werner Olle/Ulf Wolter, Die ,Große Proletarische Kulturrevolution" oder: die Objektivität der Technokratie, in: Permanente Revolution Nr. 1/2, Westberlin 1971, S. 59 ff. Vgl. zu einem ähnlichen Versuch: C. Samary, Yugoslavie: vers capitalisme ou vers le socialisme, in: Critiques de l'économie politique, N. $7 / 8$, Paris 1972 , insb. S. $267 \mathrm{ff}$. 
Bei einem solch globalen Konzept eines Staatskapitalismus stellt sich natürlich das Problem von Theorie und Geschichte, die Frage, inwieweit eine solche Theorie die je spezifischen Produktionsverhältnisse einer Gesellschaftsformation charakterisieren kann, auf sehr deutliche Weise. Hier ist zunächst zu unterscheiden, ob dabei von einer globalen Identität der Produktionsverhältnisse ausgegangen wird, oder ob unter dem Begriff des Staatskapitalismus unterschiedliche Produktionsverhältnisse gefaßt werden.

Etienne Balázs mag als Beispiel für den ersten Fall dienen, da er sowohl in horizontaler als auch vertikaler Sicht eine solch globale Identität gesellschaftlicher Entwicklung behauptet.

„Gegenwärtig sind wir Zeuge einer noch nie dagewesenen Konvergenz in der Entwicklung der unterschiedlichen Teile der Welt. Die ökonomisch unterentwickelten und vorindustriellen Länder ... werden von denselben Tendenzen durchdrungen wie die industriell vollständig entwickelten Länder.

... Man könnte diese Tendenzen ,totalitäre ${ }^{6}$ nennen und sie als eine Entwicklung definieren, die zu einem bürokratischen und technokratischen Etatismus hinführt... . Gleichgültig, ob diese Länder unterentwickelt oder hochindustrialisiert sind, überall triumphiert der organisierte Staatskapitalismus. " (20)

Vom Standpunkt dieser, gemeinsamen Tendenzen der Gesellschaften des XX. Jahrhunderts" lehrt uns dann Balázs am Beispiel Chinas auch die historische Vergangenheit besser verstehen. Er führt uns zurück bis ins III. Jahrhundert vor unserer Zeitrechnung und zeigt uns die ersten Ansätze des „bürokratischen Staates“, z. B. in „,den öffentlichen Arbeiten zur Bewässerung ${ }^{6}$, der „Omnipotenz einer Klasse von Funktionären (fonctionnaires-lettrés), die die Arbeit der ungebildeten Massen überwachen, anordnen, dirigieren und kontrollieren. "Ohne zu ,übertreiben", versichert er, „daß man diese Parallelen leicht vervielfachen könnte"(21). Man lernt so die "Parallele" zwischen ,altem" und „neuem" China fürwahr besser verstehen, denn der Staatskapitalismus erscheint

„... in China als ein reicher Greis, der seinem starken und tollkühnen Urenkel einen Schatz von äußerst wertvollen Erfahrungen hinterlassen hat." (22)

Diese Gleichsetzung aller Gesellschaftsformationen von der asiatischen Produktionsweise bis zum gegenwärtigen Kapitalismus als „Staatskapitalismus" braucht nicht weiter diskutiert zu werden, da hier offen zutage tritt, wie von der spezifischen historischen Form der Produktion abstrahiert wird.

Nehmen wir den zweiten Fall, wo der Begriff des Staatskapitalismus zwar auf unterschiedliche Gesellschaftsformationen angewendet wird, diese aber gleichzeitig nicht vollständig miteinander identifiziert werden und fragen wir erstens nach der allgemeinen Bedeutung, die man hier dem Begriff des Staatskapitalismus gibt; $z$ wei-

19) entfällt

20) Etienne Balázs, La Bureaucratie céleste. Recherches sur l'économie et la société de la Chine traditionelle, Paris 1968 , S. 44

21) ebd., S. 34, S. 165

22) ebd., S. 312 
tens nach dem Charakter der Differenzierung, die man dann zur Kennzeichnung des Staatskapitalismus in unterschiedlichen Gesellschaften vornimmt; drittens nach der Qualität, die dem Staatskapitalismus bezüglich der künftigen Entwicklung der entsprechenden Gesellschaftsformation zugesprochen wird.

Am Beispiel von Aussagen über den Staatskapitalismus in den monopolkapita. listischen und unterentwickelten Ländern soll anhand der genannten Fragestellungen auf einige allgemeine Probieme einer globalen Verwendung des Begriffs Staatskapitalismus aufmerksam gemacht werden, da diese naturlich auch für die Verwendung dieses Begriffs auf die Ůbergangsgesellschaften von Bedeutung sind (23).

„Der Staatskapitalismus, unier welchen Bedingungen er auch immer entsteht, ist nichts anderes als die Begrenzung und Regulierung ökonom ischer Naturwichsigkeit, die aus der Existenz privaten Kapitals resultiert. Er verkörpert die besondere Beziehung von Staat und Privatkapital, die entsprechend dem sozio-ökonomischen System des in Frage stehenden Landes, von urterschiedlicher Natur sein karn. . . . Ein fast vollständiges System des Staatskapitalisnus hat sich in den fortgeschrittensten kapitalistischen Ländern als staatsmonopolistischer Kapitalismus entwickelt. Hier ist das Verhältnis von Staat und Privatkapital durch die Tatsache charakterisiert, daß das private Kapital oder seine mächtigsten Fraktionen, die Monopole, den Staat kontrollieren. Staatliche Intervention firdet immer in ihrem Interesse und zum Schutz des öonomischen Gesam tsystems des Kapitalismus statt. . . .

Staatskapitalismus in den unterentwickelten Ländern unterscheidet sich vom staatsmonopolistischen Kapitalismus insbesondere wegen seiner unterschiedlichen Funktion: anstatt den naturwüchsigen Mechanismus der bereits hochentwickelten Produktivkräfte - innerhalb gewisser Grenzen - zu regulieren, hat er vielmehr zum Ziel, die Bedingungen für das rasche Wachstum der kaum entwickelten Produktivkräfte zu schaffen. Mit anderen Worten, er entsteht auf einem niedrigen Entwicklungsstand der Produktivkräfte. Auch er ist Ausdruck der Beziehung von Staat und Privatkapital, aber diese Beziehung selbst ist noch nicht determinient. Im Gegensatz zum Staatskapitalismus sowohl der entwickelten kapitalistischen wie der sozialistischen Länder, kann dieser Staatskapitalismus einen unterschiedlichen und wechselnden Klasseninhalt haben, der vom Charakter und der Wandlung im Charakter des Staates abhängt."

\section{Während der Staatskapitalismus}

„,in den kapitalistischen Ländern eine Verteidigung der kapitalistischen Produktionsweise gegen Rrisen und sozialistische Transformation zum Ziel hat, ist der Staatskapitalismus in den unterentwickelten Ländern lediglich Angriff auf oder Verteidigung gegen vorkapitalistische Formen und ausländisches Kapital. Das erklärt, warum weite Teile der Gesellschaft, die nationale Bourgeoisie und die Arbeiterklasse gleichermaßen an seiner Entwicklung interessiert sind." (24)

23) Auf die entsprechenden Aussagen des nachfolgenden Textes über Staatskapitalismus in den Übergangsgeselischaften, die hier weggelassen werden, wird in Teil II. 1 noch eingegangen.

24) Tamás Szentes, The Political Economy of Underdevelopment, Akadémiai Kiadó, Budapest 1971, S. $311-313$. Es ist erstaunlich, daß diese These von Szentes zur Unterentwicklung kritiklos in ein Buch eingegangen ist, dessen Herausgeber beanspruchen, darin ,2den politischen Impuls der Protestbewegungen" $(\mathrm{S} .9)$ aufgenommen $z$ u haben. (Gemeint ist der Beitrag von Klaus Hermann, Gesellschaftsklassen und Gesellschaf tsschichten im tropischen Afrika, in: Gesellschaf tsstrukturen, hrse. von Klaus Meschkat und Oskar Negt, Frankfurt 1973, insb. S. 314). Bei den aufgenommenen „Protestbewegun gen $^{\text {ss }}$ scheint offensichtlich die Entfaltung der kolonialen Revolution vergessen worden zu sein, die die These eines klassenindifferenten ,5 taatskapitalismus " grïndlich widerlegt hat. 
Aus diesen Aussagen lassen sich die angesprochenen Probleme entwickeln.

Erstens: Staatskapitalismus bezeichnet eine ,besondere Beziehung von Staat und Privatkapital", deren Charakter von der jeweiligen sozio-okonomischen Struktur bestimmt wird. - In diesem Gebrauch des Begriffs Staatskapitalismus ist auffallend, daß die sozio-ökonomische Struktur für die Konstituierung eines Staatskapitalismus zunächst selbst keine Rolle spielt, vielmehr diesen nur post festum charakterisiert. Der Begriff des Staatskapitalismus, der sich so außerhalb einer bestimmten gesellschaftlichen Struktur konstituiert, ist folglich nicht in der Lage, isoliert die Spezifika einer Produktionsweise zu bezeichnen. Daraus ergibt sich nun zweierlei: zum einen wird hier der Zusammenhang von "Staat" und "Kapital", eben weil er kein spezifisches gesellschaft liches Verhältnis mehr artikuliert, selbst problematisch; zum anderen ist eine quasi zusätzliche sozio-ökonomische Charakterisierung der unterschiedlichen "Staatskapitalismen" notwendig, die sich dann aber selbst nicht mehr auf eine gesellschaftliche Totalitäat beziehen kann. Beides wird in dem Text deutlich. Anstatt vom Verhältnis von Staat und kapitalistischer Gesellschaft, wird hier von einer Beziehung zwischen Staat und ,(Privat)Kapital" ausgegangen, was dazu führt, daß diese nicht mehr in einem inneren Zusammenhang, sondern lediglich als sich äußerliche Beziehung aufgefaßt wird. Staat und „Kapital ${ }^{\text {s6 }}$ wird daher nur als Entgegengesetztes (der ,regulierende" Staat - das ,naturwüchsige " Kapital), nicht aber auch als Zusammengehörendes begriffen (25). Die Ursache ist, daß „Kapital" hier nicht mehr als Kapitalverhältnis, als Moment eines gesellschaftlichen Reproduktionsprozesses erscheint. Erst das erlaubt es auch, eine „Beziehung“ von Staat und ,Kapital“ in allen Gesellschaftsformationen als Staatskapitalismus zu bezeichnen.

Zweitens: Wird so der Begriff des Staates vom Kontext der historischen Bedingungen des kapitalistischen Reproduktionsprozesses getrennt, kann sich die Kennzeichnung der unterschiedlichen ,Staatskapitalismen " nur noch auf einen differenten gesellschaftlichen Überbau beziehen. So heißt es dann auch in dem Text: Der Staatskapitalismus kann einen unterschiedlichen Klasseninhalt haben, der vom Charakter des Staates abhängt. - Werden zunächst Klassenverhältnisse nur noch in ihrer Artikulation auf der Ebene des Überbaus, hier: des Staates, begriffen, so wird im folgenden der Staat wechselnd mit dem Kapital identifiziert (in den monopolkapitalistischen Ländern) (26), bzw. gegenüber dem Kapital autonom gesetzt (in

25) Vgl. zur Kritik dieses äußerlichen Verhältnisses von Staat und Gesellschaft: Elmar Altvater, $\mathrm{Zu}$ einigen Problemen des Staatsinterventionismus, in: Probleme des Klassenkampis Nr. 3, Erlangen 1972; Wolfgang Müller/Christel Neusïß, Die Sozialstaatsillusion und der Widerspruch von Lohnarbeit und Kapital, in: Sozialistische Politik Nr.6/7, Westberlin 1970; Nicos Poulantzas/Ralph Miliband, The Problem of the Capitalist State, in: Ideology in Social Theory, hrsg. von Robin Blackburn, London 1972, S. 238 ff.

26) Die postulierte Identität von Staat und Monopolen ist in der Theorie des staatsmonopolistischen Kapitalismus durchaus nicht allgemein. Boccara wendet sich explizit gegen diese These: „Man kann... nicht von einer Verschmelzung von Monopolen und Staat sprechen, was nämlich bedeuten würde, daß wir es mit einem öffentlichen - oder Staatskapitalismus zu tun hätten." (Paul Boccara, Übersicht über die Theorie der Überakkumulation - Entwertung des Kapitals und die Perspektiven der fortschrittlichen Demokratie, in: Sozialistische Politik Nr. 16, Westberlin 1972, S. 4). Es ist allerdings lediglich dem 1. Halbsatz Boccaras zuzustimmen. 
den unterentwickelten Ländern). Aber weder ist der Staat begrifflich mit dem Kapital identisch, noch autonom von ihm; es handelt sich vielmehr um eine Form der „Besonderung“ des Staates auf der Basis kapitalistischer Produktionsverhältnisse (28), die allerdings historischen Modifikationen unterworfen ist. Hier ist lediglich von Bedeutung, daß der Begriff des Staatskapitalismus seine wesentlichen Spezifika aus der Charakteristik des gesellschaftlichen Überbaus bezieht. Das gilt über den Text von Szentes hinaus für sehr unterschiedliche Varianten dieser Theorie, etwa für Pollock's Unterscheidung zwischen ,totalitärem" und ,demokratischem" Staatskapitalismus (29), wobei hier nicht einmal mehr Klassenverhältnisse auch nur angedeutet werden.

Drittens: Der Staatskapitalismus in Form des staatsmonopolistischen Kapitalismus stabilisiere das kapitalistische System gegenüber einer sozialistischen Transformation, während er im ökonomisch unterentwickelten Land befähigt sei, die Struktur der Unterentwicklung zu beseitigen. - Der Begriff des Staatskapitalismus verweist so auf ein globales Konzept der sozialistischen Revolution, das nicht nur in sich widersprüchlich, sondern auch historisch widerlegt ist. Die These von der Stabilisierung des Kapitalismus steht in offenem Widerspruch zu der These von dessen Niedergang, an der die gleichen Theoretiker festhalten (30). Die postulierte Aufhebung der Unterentwicklung durch einen Staatskapitalismus kollidiert mit den strukturell bedingten Grenzen einer Kapitalakkumulation im unterentwickelten Land (31). Gerade die letzte These ist historisch gründich widerlegt worden und Revolutionäre aus diesen Ländern selbst haben diese „sterilen Stereotypen aus den Metropolen“"(32) theore tisch und praktisch zurückgewiesen.

27) entfälit

28) Vgl. zur Diskussion der Marxschen These von der ,Besonderung“ des Staates: Altvater, a. a. O., insbesondere S. 5-17 und Müller/Neusüß, a. a. O., S. 53 ff.

29) Friedrich Pollock, State Capitalism: Its Possibilities and Limitations, in: Studies in Philosophy and Social Science, Vol. IX, N. Y. 1941, S. 201 f.

30) Altvater, a. a. O., S. 24

31) Obwohl für Szentes der ,Staatskapitalismus“ im unterentwickelten Land selbst schon eine ,progressive“, weil die Bedingungen der Unterentwicklung aufhebende Tendenz darstellt, sind bezüglich der künftigen Entwicklung verschiedene „Metamorphosen" dieses "Staatskapitalismus" möglich: 1. Rückkehr zum "national private capitalism"; 2. Entwicklung zum ,state monopoly capitalism" (z. B. Brasilien); 3. Übergang zum "socialist system of state planned economy", wobei letzteres "the non-capitalist way of further development", ,the overture to socialist development without, or more exactly before, a socialist revolutionary transformation" darstelle (Szentes, a.a.O., S. 313-318). Die Unmöglichkeit aller drei Alternativen ist offensichtlich: weder ist im unterentwickelten Land aufgrund der Polarität und der Einbeziehung der unterentwickelten Lander in den Weltkapitalismus eine ,nationale ${ }^{66}$ Kapitalakkumulation möglich, die die Unterentwicklung aufhebt - noch kennzeichnen die industriellen Metropolen im unterentwickelten Land die gesamte Produktionsweise, die gerade durch diese interne Polaritait, d. h. internen Mehrwerttransfer, gekennzeichnet ist - noch gibt es die Idylle eines ,nicht-kapitalistischen ${ }^{6}$ Entwicklungsweges, was sich etwa an der chilenischen Entwickiung zeigen ließe. Vgl zu diesen Problemen z. B. Pierre Salama, Le procès de ,sous-développenent", Essai sur les limites de l'accumulation nationale du capital dans les économies semi-industrialisées, Paris 1972, insb. S. $143 \mathrm{ff}$.

32) André Gunder Frank, Die Entwicklung der Unterentwicklung, in: Kritik des bürgerlichen Anti-Imperialismus, Westberlin 1969, S. 44 
Diese Problematisierung eines globalen Konzepts eines Staatskapitalismus hat so drei wesentliche Charakteristika des Begriffs des Staatskapitalismus erbracht:

- $\quad$ seinen ahistorischen Charakteĩ, insofern er die spezifisch historische Form der Produktion negiert;

- seinen ideologischen Charakter, insofern er seine wesentlichen Kennzeichen aus dem gesellschaftlichen Überbau, der konkreten Form der „Besonderung“" des Staates in der kapitalistischen Gesellschaft, bezieht;

- seinen praxisorientierten Charakter, insofern er Aussagen über den Erhalt bzw. die Revolutionierung einer bestimmten Gesellschaftsformation impliziert.

Diese drei Bestimmungen sind auch für den Fortgang dieser Arbeit von Bedeutung, da sie nochmals unterstreichen, daß es nicht ausreicht, die Enthistorisierung von Theorie lediglich zu konstatieren. Deren Möglichkeit ist zum einen in den materiellen gesellschaftlichen Verhältnissen selbst begründet, zum anderen ist sie immer auch verschlïsselter Ausdruck von Praxisformen. Die Enthistorisierung der Theorie ist so selbst historisch bedingt: durch die jeweiligen gesellschaftlichen Verhältnisse und die agierenden geschichtlichen Subjekte. die agierenden geschichtlichen Subjekte.

\subsection{Zum Begriff des Staatskapitalismus}

Wenn damit zugleich abgelehnt wird, die Enthistorisierung von Theorie auf subjektive Irrtümer (etwa ein „falsches“ Verständnis bestimmter Kategorien) zu reduzieren, so heißt das natürlich umgekehrt nicht, daß eine kategoriale Kritik der Theorie des Staatskapitalismus nicht möglich ist. Einige der Probleme, die bei einer kategorialen Kritik zu thematisieren wären, müssen hier - wenn auch nur sehr oberflächlich - berührt werden, da im folgenden immer wieder Aussagen zitiert werden müssen, in denen der Begriff des Staatskapitalismus sehr unterschiedlich gebraucht wird.

Leontjew etwa kennzeichnet als Staatskapitalismus folgende Erscheinungsformen:

"1. Unternehmung der öffentlichen Hand; 2. verschiedene Formen staatlicher Regelung der Tätigkeit privater Unternehmungen (hauptsächlich in Bezug auf Preisbildung); 3. die Sphäre der zwischenstaatlichen Beziehungen; 4. die Sphäre der sogenannten Sozialpolitik (vor allem das Schlichtungswesen und die Arbeitsgesetzgebung)." (33)

Hierbei ist zunächst wichtig (34), daß sich auf Basis kapitalistischer Produktionsverhältnisse der gesellschaftlichen Zusammenhang nur in der Konkurrenz der Einzelkapitale durchsetzt, was gerade den Staat als ,, besondere " Existenz zur Wahrnehmung bestimmter gesellschaftlicher Funktionen notwendig macht; Funktionen, die auf-

33) L. Leontjew, Der ,organisierte Kapitalismus ${ }^{6}$ und die ,Wirtschaftsdemokratie', in: Unter dem Banner des Marxismus, III. Ig., Wien 1929, S. 675 f.

34) Im folgenden Abschnitt werden wichtige Ergebnisse der Arbeit von Altvater, a. a. 0 , S. $1-24$ referiert. 
grund der jeweiligen Sonderinteressen durch Einzelkapitale nicht wahrgenommen werden können (dazu gehören die von Leontjew zitierten Punkte 2-4). Plausibler scheint die Verwendung des Begriffs Staatskapitalismus bezüglich des verstaatlich ten Sektors zu sein. Aber auch hier bleibt dieser Begriff problematisch, solange die Funktion dieses Sektors nicht im einzelnen aus dem historisch definierten Gesamtreproduktionsprozeß bestimmt wird, $d . h$. analysiert wird, ob es sich dabei um die Herstellung der „allgemeinen Bedingungen der Produktion" (35) handelt, wobei hier der Staat gerade ,nichtkapitalistisch agiert" oder um Sektoren, in denen sich der Staat als ,wirklicher" Kapitalist betätigt. Nur im letzteren Fall könnte von "Staatskapital" gesprochen werden (36).

Gerade die spezifischen Reproduktionsbedingungen im unterentwickelten Land verleiten dazu, zum einen undifferenziert vom ,staatskapitalistischen ${ }^{6}$ Sektor zu sprechen, zum anderen diesen aus dem Gesamtreproduktionsprozeß zu lösen. Hierzu zwei Beispiele. Bezüglich der mexikanischen Entwicklung heißt es etwa bei Trotzki:

.Die gegenwärtige Politik ist in dem zweiten Stadium; die größten Eroberungen sind die Enteignungen der Eisenbahnen und der Ölindustrie. Diese Maßnahmen sind ganz im Rahmen des Staatskapitalismus." (37)

Oder etwa Córdova/Michelena:

„Für Venezuela haben wir drei Varianten des kapitalistischen Systems (eine externe monopol1.apitalistische, eine interne privatkapitalistische und eine staatskapitalistische) als drei verschiedene Sektoren bestimmt."

Die Problematik einer solchen Trennung ist den Autoren allerdings selbst bewußt, wenn sie anmerken:

,Selbstverständlich mưßste man hier diskutieren, ob das externe kapitalistische, das interne kapitalistische und das staatskapitalistische System als verschiedene Systeme oder als Varianten ein und desselben Systems zu betrachten seien. Für die Analyse der Struktur ist es inserer Meinung nach aus operativen Gründen besser, von drei verschiedenen Systemen zu sprechen." (38)

Von einer Produktionsweise als von einem Staatskapitalismus zu sprechen, hätte demnach nur Sinn, wenn tatsächlich Staatskapital - in dem oben präzisierten Sinn - dominierende Kapitalform einer Gesellschaft ist.

Dieses Staatskapital bliebe Teil eines gesellschaftlichen Gesamtkapitals, folg-

35) Marx, Grundrisse .., a. a. O., S. $429 \mathrm{ff}$.

36) Szentes spricht sogar von, Staatsakkumulation": "Industrialization needs enormous sources of accumulation. The private, capitalist way of accumulation cannot ensure them. What is needed is concentrated social accumulation, state accumulation." (Szentes, a. a. O., S. 308)

37) Leo Trotzki, Verstaatlichte Industrie und Arbeiterverwaltung, wiederabgedruckt in: Solidarität, hrsg. von der Revolutionary Communist Party, Nr. 49, London 1948, S. 1

38) Armando Córdova/Héctor Silva Michelena, Die wirtschaftliche Struktur Lateinamerikas. Drei Studien zur politischen Ökonomie der Unterentwicklung, Frankfurt 1969, \$. 76 
lich auch der Konkurrenz unterworfen (39). Kapital im Sinne einer homogenen Entität, einen ,kollektiven Kapitalisten" Staatskapitalismus-Theoretikern vertreten wird - kann es nicht geben (40). Aber kann Staatskapital überhaupt zur dominierenden Kapitalform werden? Hier ist zu bericksichtigen, daß jede Ausdehnung des staatlichen Sektors auf Kosten privater Kapitalverwertung erfolgt und insofern gerade Zersetzungserscheinungen und damit veränderte allgemeine Bedingungen kapitalistischer Produktion beweist. Diese Ausdehnung des staatlichen Sektors wäre demnach nicht identisch mit einer Ausdehnung des Staatskapitals.

Die Problematisierung einer globalen Verwendung des Begriffs Staatskapitalismus hatte gezeigt, daß diese Verwendung nur infolge der Abstraktion von den je unterschiedlichen Bedingungen gesellschaftlicher Reproduktion möglich ist. Als Ergebnis der kategorialen Überprifung hat sich zudem ergeben, daß der Begriff des Staatskapitalismus zur Kennzeichnung der Totalität eines sozio-ökonomischen Systems bzw. bestimmter vom Staat wahrzunehmender gesellschaf ticher Funktionen analytisch falsch ist, (er nur für jeweils historisch definierte Bereiche, wo der Staat als wirklicher Kapitalist agiert, berechtigt ist).

Von daher ist der Begriff des Staatskapitalismus (in der kritisierten Verwendung) wesentlich als ideologischer Begriff zu interpretieren, der zugleich bestimmte Praxisformen verhüllt. Deren Dechiffrierung aber ist nur möglich, wenn Genesis und Entwicklung der Theorie des Staatskapitalismus rekonstruiert werden.

\subsection{Die Genesis der Theorie des Staatskapitalismus aus der Kritik des ,Staats- sozialismus" ",Kriegssozialismus"}

Begriff und Theorie des Staatskapitalismus verdanken ihren Ursprung einer spezifischen Interpretation bestimmter Tendenzen kapitalistischer Entwicklung, die als Keim einer gedachten, sozialistischen Gesellschaft erscheinen. Der Begriff des Staatskapitalismus ist so nicht nur bloße Deskription kapitalistischer Entwicklung, sondern orientiert sich von Anfang an am Anspruch ihrer Negation, des Übergangs zu einer höheren Produktionsweise. Kein Wunder, daß dieser Begriff in der Arbeiterbewegung entsteht. Aber die Genesis des Begriffs Staatskapitalismus selbst ist nicht unmittelbarer Ausfluß einer veränderten Wirklichkeit, sondem vermittelt

39) Vgl. Karl Marx, Grundrisse ..., a.a. O., \$. 317. Zum Begriff des gesellschaftlichen Gesamtkapitals vgl. etwa Karl Marx, Das Kapital, III. Band, MEW 25, Berlin/DDR 1969. S. $182 \mathrm{ff}$.

40) Friedrich Engels hat durch seine Formulierung: „Je mehr Froduktivkräfte er (der Staat - d. Verf.) in sein Eigentum ubernimmt, desto mehr wird er wirklicher Gesamtkapitalist..." (Friedrich Engels, Die Entwicklung des Sozialismus von der Utopie zur Wissenschaft, in: MEW 19, S. 222) dieser Interpretation Vorschub geleistet. Diejenigen, die sich auf Engels berufen, abstrahieren gwöhnlich von den materiellen Bedingungen des damaligen deutschen Kapitalismus, die Engels im Auge hatte. Vgl. etwa Max Horkheimer, Autoritärer Staat, geschrieben 1940, in: Kritische Theoric der Gesellschaft, Bd. III, Frankfurt 1968, insb. \$. 35 f., Tony Cliff, Russia. A marxist analysis, London 1964 , S. 114 
durch die Kritik eines anderen Begriffs, den des ,Staatssozialismus" (41).

Die Gegenüberstellung von "Staatssozialismus" und "Staatskapitalismus" wird bisweilen dazu benutzt, die Trennungslinie zwischen lassalleanischer und marxistischer Staatstheorie zu markieren und zu beleger, ,daß sich in der Frage des Etatismus und des Staates Marxismus und Lassalleanismus unvereinbar gegenüberstehen" (42). Abêr diese bloß ideelle Konfrontation von lassalleanischer und marxistischer Staatstheorie erklärt noch nicht die Genesis des Begriffs Staatskapitaiismus.

Denn das Problem um ,Staatssozialismus",,Staatskapitalismus" erhält in der deutschen Arbeiterbewegung im wesentlichen erst nach 1890 Bedeutung, als das Sozialistengesetz nicht mehr erneuert wird. Denn jetzt erst beginnt die Tatsache, daß ,der Staat in der Person des Kaisers der Arbeiterbewegung die sozialpolitische Hand entgegen(ge)streckt ${ }^{\text {" }}$ hatte, ihre Auswirkungen in Teilen der Sozialdemokratie zu zeitigen, nachdem ihnen Bismarck ,,zwölf Jahre lang den Etatismus mit Kolben stößen und Zuchthausurteilen" ${ }^{64}(4)$ ausgetrieben hatte.

Dieser politische Wandel vollzieht sich zudem unter den Bedingungen eines sich entwickelnden deutschen Kapitalismus, einer immensen Konzentration und Zentralisation der Kapitale (45), für deren Expansion der bürgerliche Staat die allgemeinen Bedingungen der Produktion herstellt.

„Man pflegt in diesem Zusammenhang in erster Linie an die neuen Maßnahmen der Zoll- und Sozialpolitik zu denken, die einerseits der veränderten Weltmarktstellung der deutschen Nahrungsmittel- und Rohstoffwirtschaft, andererseits dem gesteigerten Tempo der Industrialisierung entsprangen." (46)

Unter diesen Bedingungen werden Verstaatlichungen im Eisenbahnwesen, Wasserstraßenbau, Steinkohlen- und Kalibergbau, Elektrizitätswirtschaft und Bankwesen durchgeführt bzw. projektiert (47). „Der objektiven Entwicklung der Ausbreitung des Etatismus in der Sozialökonomik entsprach also auf der subjektiven Seite... (eine)... Wandlung des sozialdemokratischen Bewußtseins... "(48). Diese beiden Entwicklungstendenzen stellen zu einem Zeitpunkt, als sich für die deutsche Arbeiterbewegung die Frage einer Beurteilung der praktischen Verstaatlichungspolitik stellt, den Hintergrund dar, der die Entstehung des Begriffs des Staatskapitalismus provoziert.

Denn unter dem Eindruck dieser skizzierten Entwicklung wähnen sich Teile der sozialdemokratischen A rbeiterbewegung bereits in den Vorhallen eines, ,Sozia-

41) „Der Gleichsetzung des Staatskapitalismus mit dem Sozialismus ging die des Sozialismus mit dem Staatskapitalismus voraus." (Paul Mattick, Marx und Keynes, Frankfurt 1971, S. 302)

42) Willy Huhn, Etatismus, Kriegssozialismus", Nationalsoziälismus in der Literatur der deutschen Sozialdemokratie, in: Neue Kritik Nr. 55/56, Frankfurt 1970, S. 76

43) entfällt

44) Huhn, a. a. O., S. $80 \mathrm{f}$.

45) Zum Unterschied der beiden Regriffe vgl. Karl Marx, Das Kapital, I. Band, MEW 23, Berlin/DDR 1969, S. 653 ff.

46) Hans Staudinger, Der Staat als Unternehmer, Berlin 1932, S. 25

47) Vgl. ebd., S. 25 ff.

48) Huhn, a. a. O., S. 86 
lismus", eines, ,Zukunftstaates“ (49), dem der preußische Staat den Weg bahne. So formuliert etwa Georg von Vollmar 1892 ,

,daß der hestehende Staat nicht bloß eine Organisation zu politischen Zwecken sei, sondern daß sich seine Souveränität auch auf das wirtschaftliche Gebiet in dessen vollem Umfange erstrecke ..." ",

wobej

„die Entwicklung in Deutschland längst jede Gefahr, welche aus einer Benützung des Staatssozialismus zu machtpolitischen Zwecken entstehen konnte, beseitigt hat . . " "

und daher

,die Sozialdemokratie keinerlei Grund hat, den Gedanken des Staatssozialismus an sich mit besonderem Eifer zu bekämpfen。“ (50)

Diese Aussagen implizierten die These yon der, Möglichkeit allmählicher innerer Umgestaltung (des States) im Sinne der aufstrebenden Klassen" (51):

"Der Staat, und wenn er noch so wenig schon als vollkommen demokratischer Staat zu bewerten wäre, ist ... als Gruben-, Hochofen- und Walzwerkbesitzer stets weitergespannteren, allgemeineren, bis zu einem gewissen Grade volkstümlicheren Interessen mit unterstellt, und seine ganze Entwicklungsgeschichte läuft unbestreitbar auf eine Verstärkung dieses seines allgemeineren klassengemischteren Gepräges, mit immer unwiderstehlicherer Anteilnahme der Arbeiter hinaus. " $(52)$

Der Reiz, qua Verstaatlichung auch zu ,klassengemischteren“ ökonomischen Einheiten $\mathrm{zu}$ gelangen, entsprang insbesondere der Expansion privater Monopole, die einerseits schon damals ,einen hochgradig gemeingefährlichen Standpunkt" (53) erreichten, andererseits ,wesentliche Vorarbeit für die Vergesellschaftung" ${ }^{64}(54)$ der Produktion leiste ten. Die daher geforderte ,gesellschaftliche Kontrolle" (55) bzw. ihre Umwandlung in Staatsmonopole sollte eine erste Phase des sozialdemokrati. schen Kampfes darstellen, während in einer zweiten Phase dann ,um die Gestaltun-

49) Die Befürworter eines „Staatssozialismus " begriffen die künftige Gesellschaftsordnung bezeichnenderweise als „Zukunftsstaat". Welche „Perlen diese Gemälde vom ,Zukunftsstaat ${ }^{66}$ hervorbrachten, erwähnt Huhn, a. a. O., S. 85: so bezieht sich etwa der Sozialdemokrat Theodor Reese (Der Zukunftsstaat, Hamburg 1905) auf den Sonnenstaat Campanellas und tröstet den diesseitigen, sich plagenden Arbeiter, er werde im ,Zukunftsstaat bei einer halbstündigen Tätigkeit in hohem Wohlstand, von Luxus umgeben ${ }^{66}$ leben.

50) Georg von Vollmar, Ủber Staatssozialismus, Nürnberg 1892, zitiert nach: Huhn, a.a.O., S. 77

51) Max Schippel, Parteigeschichtliche Rückblicke, in: Monopolfrage und Arbeiterklasse, hrsg. von Wilhelm Jansson, Berlin 1917, S. 179.

52) ebd., S. 201

53) ebd., S. 206

54) Wilhelm Jansson, Für oder wider die Monopole, in: Monopolfrage . . , a. a. O., S.226

55) ebd., S. 227. In diesem Text wird durchgängig, gesellschaftlich" mit, staatlich "gleichgesetzt. 
gen der Staatseinrichtungen selbst ${ }^{\text {" }}(56)$ gerungen werden sollte.

Diese Konzeption eines ,Staatssozialismus" begründete in der Konsequenz eine evolutionäre Entwicklung, wobei die These, daß ,nur ein allmählicher Umbildungsprozeß eine höhere Wirtschaftsordnung zu schaffen vermöge" (57), eine wesentliche Voraussetzung hatte, eben: „daß der Staat selber in seinem Wesen und Verhalten einem ununterbrochenen Wandel unterliegt " (58). In pragmatischer Hinsicht plädierten die Vertreter eines,, Staatssozialismus ${ }^{66}$ für Verstaatlichungen durch den bürgerlichen Staat - mit dem subtilen, Nebengedanken, hierdurch der späteren Vergesellschaftung vorzuarbeiten." (59)

Die Argumente gegen diese Konzeption eines "Staatssozialismus" bezogen sich wesentlich auf den darin postulierten Charakter des Staates und die Auswirkungen von Verstaatlichungen auf den Kampf der Arbeiterklasse. So kritisiert etwa Karl Kautsky in seiner Erwiderung an Vollmar:

„Weder das Proletariat noch die Kapitalistenklasse soll durch ihn (den Staatssozialismus) aufgehoben, sondern das Verhältnis zwischen beiden ein für allemal unverrückbar von Staats wegen festgesetzt werden ... Der Staat bleibt eine über dem Arbeiter stehende Macht, deren Interessen von seinen ver schieden sind." $(60)$

\section{Kennzieichnet Kautsky so die Vorstellung eines „Staatssozialismus“ als}

„eine ideologische Ausdrucksform für den Versuch, den Klassenkampf des Proletariats noch innerhalb der kapitalistischen Klassengesellschaft aufzuheben bzw. unmöglich zu machen ' (61),

so fragen andere Kritiker nach den Auswirkungen, die diese Konzeption eines „Staatssozialismus“ für den Klassenkampf habe, wenn sie sich in der Wirklichkeit durchsetzt. Wilhelm Liebknecht erkennt in einer solchen Entwicklung eine Tendenz zur Potenzierung der ökonomischen und politischen Macht der Bourgeoisie:

„Wenn der heutige Staat verstaatlicht, so bleibt der Staat, was er jetzt ist. Er tritt als Arbeitgeber an die Sielle der Privaten, und die Arbeiter gewinnen dabei nichts, wohl aber hat der Staat seine Macht und seine Unterdrückungskraft gestärkt ... und hätte der Staat alle Betriebe in der Hand, so würde der Arbeiter, da er keine andere Beschäftigung finden könnte, sich jeder Bedingung zu fügen haben. Und wie die ökonomische, so wird auch die politische Abhängigkeit durch diesen sogenannten Staatssozialismus, der in Wirklichkeit Staatskapitalismus ist, nur im denkbar höchsten Maße verschärft, und die ökonomische Sklaverei würde die politische, die politische die ökonomische steigern und intensiver machen ... " (62)

Orientierten sich diese Argumente Liebknechts an den Auswirkungen verstaatlichter Produktion auf Lohnkämpfe und Klassenbewußtsein, so führt Jules Guesde in einer analogen Debatte in der französischen Sozialdemokratie ein Argument an, das auf 56) ebd., S. 237

57) Schippel, a. a. O., S. 215 f.

58) ebd., S. 216

59) Jansson, a. a. O., S. 238

60) Karl Kautsky, Dex Parteitag und der Staatssozialismus, in: Die Neue Zeit, Wochenschrift der deutschen Sozialdemokratie, XI. Jg., I. Band, 1892-93, S. 214

61) So faßt Huhn, a. a. O., S. 79, die Kautskysche Kritik zusammen.

62) Wilhelm Liebknecht, Staatssozialismus und revolutionäre Sozialdemokratie, Referat auf dem Berliner Parteitag der SPD 1892, zitiert nach: Monopolfrage ..., a. a. O., S. $172 \mathrm{f}$. 
einen veränderten Funktionsmechanismus kapitalistischer Produktion (und damit veränderten Bedingungen der Revolutionierung dieser Produktionsverhältnisse) hinweist:

„Jede vom Staat einheitlich geleitete Industrie ist den Katastrophen entzogen, mit denen das Schlachtfeld der Privatindusirie sich bedeckt ... So viele Gemeinbetriebe sich durchsetzen, so viele Gefahrenquelien sind für die kapitalistische Klasse beseitigt, und ebenso viele Gewinnchancen sind der Arbeiterkiasse entzogen, deren befreiende Hoffnung nur aus dem kapitalistischen Drunter und Druber ... entspringen kann." (63)

Bezogen auf den pragmatischen Kontext - Bejahung oder Verneinung von Verstaatlichungen durch den bürgerlichen Staat - schien die Konzeption eines, Staatssozialismus" zu einer Ersetzung der proletarischen Revolution durch Schaffung von Gemeinbetrieben durch den bürgerlichen Staat zu tendieren, während ihre Kritiker formulierten: ,erst die Revolution ... dann die Gemeinbętriebe" (64).

Diese Skizzierung des Konflikts um ,Staatssozialismus" oder ,Staatskapitalismus" ermöglicht es, die Genesis des Begriffs Staatskapitalismus (von einer Theorie kann hier noch nicht gesprochen werden) zu präzisieren. Gegenüber der Interpretation von Verstaatlichungen durch den bürgerlichen Staat als ,Staatssozialismus “, als „Sieg des sozialistischen Prinzips" (65) innerhalb der kapitalistischen Gesellschaft und der damit möglich gewordenen evolutionären Entwicklung zum „Sozialismus“, stellt der Begriff des Staatskapitalismus einen korrekten Rekurs auf die marxistische Theorie dar. Aber der Begriff des Staatskapitalismus ist nur vermittelter Ausdruck von Wirklichkeit, nicht die ideelle Reproduktion dieser Wirklichkeit selbst. Er ist in seinem Ursprung ein dem Begriff des, ,Staatssozialismus“ entgegengesetzter, nur durch ihn verstehbarer und nur als dessen Kritik ,präziser" Begriff.

Bezieht sich zudem in dieser Periode kapitalistischer Entwicklung der Begriff des ,Staatskapitalismus“ wesentlich auf einen ,Zukunftsstaat", der aus gegenwärtigen Maßnahmen des bürgerlichen Staates extrapoliert wird, so auch dessen Kritik als „Staatskapitalismus".

Der Begriff des Staatskapitalismus ist infolgedessen auf dieser Stufe seiner Entwicklung doppelt einer Reproduktion von Wirklichkeit entzogen: durch seine Entgegensetzung zu einem anderen Begriff und dessen Bezug auf eine künftige Gesellschaft.

Aber bereits zehn Jahre später, 1915, schreibt ein der Mehrheitssozialdemokratie nahestehender O̊konom:

"Ich glaube, daß sich so manche deutsche Arbeiter, deren Gewerkschaften mit so kluger Überlegung und starkem Einfluß an der Erhaltung unseres Wirtschaftslebens mitarbeiten, ruhig gestehen werden: anders wie dieser neue deutsche Gemeinstaat kann auch der geträumte Zukunfts-

63) Jules Guesde, Services publics et Socialisme, zitiert nach: Monopolfrage ..., a. a. O., S. $178 \mathrm{f}$.

64) Guesde, ebd., S. 179. Diese Position von Guesde war sicherlich nicht durchinehend kennzeichnend für alle Kritiker des "Staatssozialismus". Uber das oft widersprüchliche Verhalten der deutschen Sozialdemokratic in der Frage der Verstaatlichung informiert Schippel, a. a. O., S. $179 \mathrm{ff}$.

65) Jansson, a. a. O., S. 240 
Dieser, ,neue deutsche Gemeinstaat" war der sich im Krieg befindende deutsche Imperialismus: der "Gemeinstaat" der Obersten Heeresleitung. Dessenungeachtet rief er in Teilen der deutschen Sozialdemokratie und der Gewerkschaften helle Begeisterung hervor:

„Eine neue Zeit ist angebrochen, andere Menschen hat der Krieg in kurzer Zeit aus uns allen gemacht. Das gilt unterschiedslos für hoch und niedrig, für arm und reich, für Privatpersonen und Staatsdiener. Solidarität und Hilfeleistung aus unverschuldeter bitterer Not, die wir den Arbeitern als unvergängliche Richtschnur des Handelns eingeimpft haben, ist über Nacht Gemeingut eines großen und leistungsfähigen Volkes geworden. Sozialismus, wohin wir blicken." (67)

Blicken wir. Mit der imperialistischen Entwicklung des deutschen Kapitalismus und der Vorbereitung auf den I. Weltkrieg treten einschneidende Veränderungen in den Reproduktionsbedingungen des deutschen Kapitals ein, die vermittelt sind durch die Weltmarktentwicklung des Kapitals. Der Krieg, als einer Ausdrucksform der Konkurrenz der nationalen Kapitale, destruiert vorübergehend deren Weltmarktzusammenhang, setzt so für den Reproduktionsprozeß des Kapitals auf nationaler Ebene (sowohl für dessen stoffliche als auch wertmäßige Seite) neue Bedingungen und macht dadurch veränderte gesellschaftliche Funktionen des Staates notwendig. Ihre bekannten Erscheinungsformen:

„,Die Schaffung von staatlichen Monopolen (in Produktion und Handel), die Organisierung von sogenannten ,gemischten Betrieben', in denen Staat oder Kommune neben privaten Syndikaten oder Trusts als Teilhaber figurieren; die staatliche Kontrolle über den Produktionsprozeß der privaten Betriebe (Zwang zur Produktion, Regulierung der Erzeugnismethoden, usw.), Regulierung der Verteilung (Zwang zur Lieferung und Annahme von Produkten, Organisierung von staatlichen ,zentralen Verteilungsstellen', staatliche Lager für Rohstoffe, Brennstoffe, Lebensmittel, Festsetzung von Höchstpreisen, Brot-, Fleisch- und sonstige Karten, Verbot der Ein- und Ausfuhr, usw.), die Organisierung des staatlichen Kredits und endlich die Organisierung der Konsumtion durch den Staat (städ tische Küclien)." (68)

Die ahistorisch-deskriptive Fassung dieser Erscheinungsformen als staatliche „Organisierung " oder „Regulierung" (69) abstrahiert nicht nur von den veränderten allgemeinen Bedingungen der Produktion, sie verdeckt zudem, daß sich diese Maßnah-

66) Johann Plenge, Der Krieg und die Volkswirtschaft, Münster i. W. 1915, zitiert nach: Huhn, a. a. O., S. 96

67) Metallarbeiterzeitung, Organ des Deutschen Metallarbeiterverbandes, 7.11.1914, zitiert nach: Johannes Kämpfer (Pseudonym für Julian Marchlewski), Kriegssozialismus in Theorie und Praxis, Bern 1915, \$. 7

68) Nikolai Bucharin, Imperialismus und Weltwirtschaft (1915), Wien/Berlin 1929, \$. 167 f.

69) Der Begriff der staatlichen "Organisierung" der Produktion hat dann auch bei anderen zur Gleichsetzung von ,Organisation ${ }^{68}$ und ${ }_{3}$ Sozialismus ${ }^{66}$ geführt. Zu Bucharins eigenem „Standpunkt der gesellschaftlichen Organisationstechnik" (Ökonomik der Transformationsperiode (1920), Reinbek 1970, S. 64) vgl. Teil I.4, dessen Affinität zur Bogdanowschen ,Organisationswissenschaft" vgl. B. Borilin, Lenin über die ,Ökonomik der Transformationsperiode", in: Unter dem Banner des Marxismus, III. Jg., Heft 6, Wien/Berlin $1929, \mathrm{~S} .911 \mathrm{ff}$. 
men einer ,Mobilmachung der Industrie ${ }^{66}$ wesentlich auf die Distribution der durch den Kriegsbedarf ,knapp“" gewordenen Rohstoffe und Lebensmittel konzentrieren. Lediglich in zwei Produktionsbereichen, der Stickstoff- und Aluminiumindustrie, in denen das private Kapital keine Verwertungsmöglichkeiten sieht, ersetzt staatliche Produktion unmittelbar die private (70). So kommt denn auch ein preußischer Staatssekre tär zu der nüchternen Beurteilung:

„In Wirklichkeit bedeutet die Kriegswirtschaft weder eine Abkehr vom kapitalistischen \$ystem, noch auch nur eine planvolle Fortsetzung früherer Ansätze. Sie war ein Gebilde der Not."

Die staatlichen Maßnahmen bewiesen deutlich, daß

„die ,Kriegswirtschaft" kein planvoll durchdachtes System zum Zweck der Umformung der kapitalistischen Wirtschaft darstellte, sondern eine fallweise Anpassung der Formen der Güterverteilung, in geringerem Maße auch der Gütererzeugung, an die durch den Vorrang des Heeresbedarfs und den sinkenden Versorgungsspielraum geschaffene Lage."

Und bezüglich der Rolle der ,privaten Wirtschaftsorganisationen“ fügt er hinzu:

„Sie waren es, die mit zunehmender Dauer des Krieges die der Form nach staatlichen Funktionen tatsächlich ausübten und in ihren führenden Persönlichkeiten die eigentlichen Leiter der Kriegswirtschaft stellten." (71)

Diese Worte des Herrn Staatssekretärs aus dem Hause Preußen sollte man in Erinnerung behaiten, wenn im folgenden Positionen aus der deutschen Arbeiterbewegung skizziert werden, für die sich angesichts der Kriegsvorbereitungen nicht nur die Frage ihres praktischen Verhaltens, sondern damit zusammenhängend auch die Frage nach dem Charakter dieser staatlichen Maßnahmen und deren Bedeutung für die weitere Entwicklung des Kapitalismus stellte.

Hatten in Teilen der Sozialdemokratie schon Jahre zuvor durchaus bescheidene Ansätze zur staatlichen ,Sozialpolitik" und zur Verstaatlichung im Bereich der „Infrastruktur' ${ }^{66}$ und Grundstoffproduktion die Vorstellung eines für die künftige Entwicklung verheißungsvollen ,Sieges des sozialistischen Prinzips" erweckt, so wurde angesichts des Spektrums von kriegswirtschaftlichen Maßnahmen des Staates in ihren Köpfen das Prinzip vollends zur Wirklichkeit: zum ,,Kriegssozialismus ${ }^{66}$ eine Begrifflichkeit, die man nur zu gern dem "Volk" in den "Mund" gelegt hätte (72). Analoge Begriffe wie „Staatssozialismus", „relativer" oder „Kriegs-

70) In der Stickstoffindustrie allerdings erst, als die Bayerischen Stickstoffwerke aus Rentabilitätsgründen ihre Produktionsanlagen (trotz zugesicherter staatlicher Darlehen) nicht ausweiten; in der Aluminiumproduktion nur in ,halbstatlicher" Form: an der Vereinigten Aluminium-Werke AG sind neben dem Deutschen Reich noch die Metallbankgruppe und die Chemische Fabrik Grießheim-Elektra beteiligt. Vgl. Staudinger a. a. O., \$. 37 f.

71) ebd., S. 33, S. 37 (Staudinger war Staatssekretär im Preußischen Ministerium fîr Handel und Gewerbe.)

72) So einer der Wortführer des ,Kriegssozjalismus" ${ }^{\text {, }}$, der Sozialdemokrat Paul Lensch, in seinem Artikel "Kriegssozialismus" in der ,Frankfurter Volksstimme": ,Also Sozialismus in unserem Sinne ist es noch nicht, und der Volksmund hat ja auch für die Maßregeln, zu denen sich die Regierung seit Kriegsbeginn gezwungen sah, das gute Wort Kriegs sozialismus ge prägt." Zitiert nach: Kämpfer, a. a. 0 ., S. 56 
Staatssozialismus ${ }^{66}$, „Sozialismus der belagerten Festung ${ }^{66}$ etc. (73) verwiesen auf eine identische Interpretation: die Gleichsetzung der als "staatliche Organisierung der Produktion" begriffenen Maßnahmen mit Antikapitalismus.

Dabei regten insbesondere zwei Maßnahmen, die staatliche Höchstpreisbindung für Rohstoffe, Nahrungs- und Futtermittel und die spätere staatliche „Bewirtschaftung" von kriegswichtigen Rohstoffen und Getreide (75), zu dieser Interpretation an. Man argumentierte innerhalb der sozialdemokratischen Arbeiterbewegung etwa: die Höchstpreisfestsetzung sei ein ,Überbordwerfen von den wohlerworbenen Rechten des Individuums" ${ }^{66}$, ein "Bruch mit dem Phan tom einer durch die Gesetzgebung gewährleisteten Unantastbarkeit des Eigentums" (76), und bezüglich des sogenannten Getreidemonopols:

„Mit gebieterischer Hand stößt er (der Krieg - d. Verf.) auch die Mächtigen auf einen Weg, der schließlich einmal auch im Frieden zur Erfüllung der alten sozialistischen Forderung führen mus: Brot für alle!" (77)

„In der Tat bedeutet... die Einführung des Getreidemonopols den größten praktischen Triumph, den bisher der Sozialismus über den Kapitalismus errungen hat. Und gerade der Umstand, daß die Regierung durch ihr allzu langes Zögern bewies, wie blutsauer ihr dieser Schritt wurde, daß sie sich zu ihm erst verstand, als sie erkannte, daß nichts und gar nichts sonst

73) Diese Begriffe tauchen in Arbeiten von E. Biermann, K. J. Fuchs, E. Jaffé, F. Naumann, J. Plenge, L. v. Wiese u. a. auf, über die H. Köppe, Schriften über den Kriegssozialismus, in: Archiv für die Geschichte des Sozialismus und der Arbeiterbewegung, hrsg. von Dr. Carl Grünberg, VIII. Jahrgang, Leipzig 1919, S. 76 ff. informiert.

74) entfält

75) Zum Verständnis des sogenannten Getreidemonopols müssen einige Fakten erwähnt werden:

1) Die Preise für Weizen und Roggen wurden zwischen Juli und Oktober 1914 um $30-40 \%$ gesteigert (Weizen: 205 auf 270 Mark pro Tonne, Roggen: 170 auf 235 Mark - Preise für Berlin).

2) Die Höchstpreisfestsetzung vom 28.10.1914 limitierte den Weizen dann auf 260 , den Roggen auf 220 Mark pro Tonne.

3) Diese Höchstpreisfestsetzung galt jedoch nur für Brotkorn, nicht für Mehl. So ergibt sich eine sehr bezeichnende Bewegung der Mehlpreise (Preise in Mark pro DZtr.):

Juli 1914

August

Oktober

Dezember

März 1915
Weizenmehl

24,50

26,50

33,50

36,00

46,00
Roggenmehl

22,50

23,50

31,80

33,00

42,00

Trotz Höchstpreisfestsetzung für Getreide, die den Agrariern bereits enorme Kriegsgewinne sicherten, stiegen die Mehlpreise zwischen Oktober und März um über $30 \%$ 。

4) Nach der Verordnung zur Beschlagnahme des Getreides vom 25.1, 1915 war vorgesehen, daß đie Kommunalverbände das Mehl ankaufen und an die Bäcker weiterverkaufen, die Kriegs-Getreidegesellschaft das Getreide ankauft und dieses an die Kommunalverbände verteilt. Der Ankauf vollzog sich nach den Durchschnittspreisen zwischen 1. und 15. 1. 1915, Kommissionäre der Kriegs-Getreidegesellschaft waren Getreỉdegroßhändler ... usw. usw. (Zahlen nach: Kämpfer, a. a. O., S. 42 f.)

76) Hugo Heinemann, Die sozialistischen Errungenschaften des Krieges, Chemnitz 1914 , zitiert nach: Kämpfer, a. a. O., S. 9

77) Aus der sozialdemokratischen Presse, zitiert nach: Kämpfer, a. a. O., S. 55 
noch helfen könnte, erhöht nur die Bedeutung des Triumphs. Die kapitalistische Produktionsweise, oder genauer gesagt, die Methode der kapitalistischen Aneignung ist zusammengebrochen..." (78)

Insgesamt, so betonte man, sei Deutschland ,durch den Krieg mehr wie bisher eine sozialistische Gesellschaft geworden" (79), zwar noch nicht "vollkommen fertig", aber so werde ,der Sozialismus uberhaupt nicht in Erscheinung treten" (80). Die einfache Formel dafur, daß die Oberste Heeresleitung die Herzen von Sozialdemokraten für sich gewann, fand sich in der sehr bezeichnenden Gleichung: ,Organisation ist Sozialismus" (82).

Aber die Interpretation der Kriegswirtschaft als ,Sozialismus ${ }^{\text {s6 }}$ blieb nicht nur auf den rechten Flügel der deutschen Sozialdemokratie und der Gewerkschaften beschränkt. Auch die Einschätzung der Kriegswirtschaft durch Eugen Varga etwa weist in diese Richtung. Zwar handelt es sich für ihn bei der Kriegswirtschaft ,gegenüber der normalen kapitalistischen Wirtschaftsweise nicht um qualitativ Neuartiges, sondern nur um quantitative Verschiebungen“(83). Aber im Grunde klammert er doch einen Bereich aus (84):

„N Nur das Gebiet des staatlichen Eingriffes ins Wirtschaftsleben, welches für gewöhnlich auf ein sehr enges Gebiet begrenzt ist, dehnt sich in der Kriegswirtschaft ins Ungemessene aus." (85)

Und Varga fihrt aus:

„Die Bedeutung des Staates als wirtschaftlichen Faktors wächst in der Kriegswirtschaft ins Ungeheure, stellt die privatwirtschaftliche Tätigkeit ganz in ihren Dienst, so daß die Kriegswirtschaft viele Zige der sozialisierten Wirtschaft aufweist.

Sozíalistisch ist in der Kriegswirtschaft hauptsächlich jene Tätigkeit des Staates, welche die Allgemeinheit gegen die Profitwut der Kapitalisten beschützt." (86)

Auch für Varga ist "staatliche Organisierung der Produktion" und Kapitalismus prinzipiell unvereinbar; sie ist „das Gegenteil des Kapitalismus" oder auch ,der antikapitalistische Zug der Kriegswirtschaft" (87), die sich ,von der sozialistischen Regelung hauptsächlich durch die Zielsetzung" (88) unterscheidet. Auch hier also die Faszination vor der, ,organisierenden “ Potenz des bürgerlichen Staates, die man

78) Paul Lensch, a. a. O., zitiert nach: Kämpfer, a. a. O., S. 56

79) Plenge, a. a. O., zitiert nach: Huhn, a. a. O., S. 96

80) Lensch, a. a. O., zitiert nach: Huhn, a. a. 0., S. 56

81) entfällt

82) Plenge, a. a. O., zitiert nach: Köppe, a. a. 0.9 S. 83

83) Eugen Varga, Probleme der Kriegswirtschaft, in: Die Neue Zeit, Wochenschrift der deutschen Sozialdemokratie, 33. Jahrgang, 1. Band, Nr. 15, 15.1.1915, S. 449

84) Das zeigt sich auch an einigen sich selbst widersprechenden Stellen im Text: ,Die Grundlage der kapitalistischen Wirtschaft, die Anarchie der Produktion ... bleibt auch während der Kriegswirtschaft bestehen。" (S. 449) ,In der Kriegswirtschaft hört die Anarchie der Produktion zum erheblichen Teile auf, die staatliche Regelung ergreift fast das ganze Gebiet der Volkswirtschaft ..." (S. 459)

85) ebd., S. $449 \mathrm{f}$.

86) ebd., \$. 458

87) ebd.

88) ebd., S. 459 
mit der ,Anarchie" kapitalistischer Produktion nicht in Einklang zu bringen weiß (89).

Die Interpretation der Kriegswirtschaft als ,praktischer Triumph des Sozialismus $^{66}$ forderte eine Kritik in praktischer Absicht heraus, ging es doch dabei um eine Vorstellung, die die Entwicklung zum Sozialismus, unter Ausscheidung des Klassenkampfs nach den Regeln des Burgfriedens ${ }^{66}$ empfahl und zu der Schlußfolgerung führte, „, daß die proletarische Bewegung mit ihrer leidenschaftlichen Bekämpfung des Krieges eine große Torheit beging "(90). Auch hier wird deutlich, daß, wenn einem ,Kriegs" ${ }^{66}$ - oder ,Staatssozialismus" der Begriff des Staatskapitalismus entge. gengesetzt wird, dieser immer auf bestimmte Praxisformen verweist.

Allerdings handelt es sich jetzt bei der Verwendung des Staatskapitalismus-Begriffs nicht nur um die praxisorientierte Kritik falscher Aussagen über Wirklichkeit. Vielmehr vollzieht sich unter dem Eindruck der Kriegswirtschaft aus und neben der Kritik der Übergang zu einer Theorie des Staatskapitalismus. Der Begriff des Staatskapitalismus ist somit nicht mehr nur ein bloßer, korrekter Rekurs auf die marxistische Theorie, um entgegen der „Sozialismus"-Interpretation die Fortexistenz kapitalistischer Produktionsverhältnisse allgemein zu begründen, sondern reflektiert selbst positiv die spezifische Form dieser Fortexistenz und wird so selbst zum ideologischen Begriff (92), der allerdings unterschiedliche Praxisformen zuläßt.

\subsection{Die Verallgemeinerung der Theorie des Staatskapitalismus}

Die Kennzeichnung der Theorie des Staatskapitalismus als ideologische TheorieForm impliziert zweierlei: zum einen, daß die historisch außergewöhnliche Situation der Kriegswirtschaft - als ihrer materiellen Bedingung - dieser Theorie zugleich als Bild der normalen kapitalistischen Entwicklung dient und in ihr verallgemeinert wird; zum anderen, daß sich diese Theorie-Form nicht auf einzelne Theoretiker beschränkt, sondern ein allgemeines falsches Bewußtsein darstellt. Das soll im folgenden an sehr unterschiedlichen Beispielen gezeigt werden, zunächst bei Bucharin.

Zu einem Zeitpunkt, als ein Teil der sozialdemokratischen Arbeiterbewegung die Kriegswirtschaft bereits als ,Sozialismus" interpretierte, ein anderer sich für die

89) Man muß sich allerdings davor hüten, etwa die Position eines Lensch oder Plenge mit der Vargas vollständig zu identifizieren (so etwa bei Huhn, a. a. O., S. 92 ff.)

90) Kämpfer, a. a. O., S. 16

91) entfällt

92) Man kann hier sicherlich nicht von Ideologie im strengen Sirine, $d . \hbar$. als einem gesellschaftlich notwendigen falschen Bewußtsein bzw. gesellschaftlich notwendigen Schein sprechen, die als objektive Nötigung von der Organisation der Gesellschaft selbst ausgeht (vgl. Herbert Schnädelbach, Was ist Ideologie?, in: Das Argument 50, Berlin 1969, S. 83), wie es etwa bei der Lohnform der Fall ist. Ich verwende den Begriff ,,ideologisch“" dennoch, um klar zu machen, daß es sich dabei nicht um eine absichtliche Realitätsverkennung handelt, sondern die Genesis der Theorie des Staatskapitalismus materiell bedingt ist durch eine konkrete - wenn auch in dieser Gestalt historisch vorübergehende - Form der „,Besonderung ${ }^{6 /}$ des Staates. Anders läßt sich die im folgenden Teil I.4 dargestellte „Verallgemeinerung" nicht erklären. 
Zeit nach dem Kriege wenigstens, ,eine Ära neuer Hoffnungen und Erwartungen innerhalb des Kapitalismus" (93) wünschte, war der Versuch Bucharins wichtig, zu zeigen, daß der Krieg nur spezifische Erscheinungsform der Widersprüche des Kapitalismus in seiner imperialistischen Entwicklungsphase ist und diese im Krieg eklatierten Widersprüche folglich auch mit einem "Friedensschluß" nicht verschwinden (94). Zugleich aber schreibt Bucharin 1915:

„Die Bedürfnisse des Krieges und der imperialistischen Kriegsvorbereitungen drängen die Bourgeoisie zu einer neuen Form des Kapitalismus, zur Verstaatlichung der Produktion und Verteilung, zur endgültigen Vernichtung des bürgerlichen Individualismus. Natürlich werden nicht alle Maßregeln der Kriegszeit auch nach dem Kriege bestehen bleiben . . A ber ebenso unzweifelhaft ist, daß die Tendenz zur Beherrschung der Produktion durch den Staat immer stärker werden wird." (95)

Wird hierin einerseits sichtbar, daß der Krieg nicht als ,außerökonomisches" oder ,naturwüchsiges ${ }^{66}$ Faktum interpretiert werden kann, so andererseits doch zugleich die Schwäche einer ,falschen Verallgemeinerung" (96), die aus Veränderungen im Überbau eine "neue Form des Kapitalismus" folgert. Denn das impliziert, daß aus einem Teil der Wirklichkeit ein Modell ihrer Totalität erstellt wird, das dann aber eben diese Wirklichkeit nicht mehr reproduzieren kann. Bucharins Modell des „,staatskapitalistischen Trusts“ (97) versteht sich denn auch als, ,eine(r) Typus der okonomischen Verhältnisse (98). Es ist evident, daß dieser methodische Ansatz auch zu analytischen Fehlern und Widersprüchlichkeiten führen muß (99).

93) Karl Kautsky, Zwei Schriften zum Umlernen, in: Neue Zeit, 33. Jg., 2. Band, Nr. 5, 30. 4. 1915, S. 145; die Schrift, in der Kautsky einen ,Ultraimperialismus" für , ,denkbar" hält.

94) Trotz der scharfen Kritik an Buchar ins Imperialismustheorie, die Lenin insbesondere auf dem VIII. Parteitag der KPR(B) äußert, hebt er in seinem Vorwort zu Bucharins "Imperialismus und Weltwirtschaft" gerade diesen Aspekt hervor.

95) Bucharin, Imperialismus und Weltwirtschaft, a. a. O., S. $174 \mathrm{f}$

96) So kritisiert Lenin auf dem VIII. Parteitag der KPR (B) Bucharins Imperialismustheorie, vgl. W. I. Lenin, Bericht über das Parteiprogramm, in: A usgewählte Werke Band III, Berlin/DDR 1970, S. 183. Den Kernpunkt seiner Kritik formuliert Lenin als: „A uf dem Standpunkt stehen, es gäbe einen einheitlichen Imperialismus ohne den alten Kapitalismus, heißt das Gewünschte für die Wirklichkeit nehmen... Der Imperialismus ist ein Überbau über den Kapitalismus. "(ebd., S. 186)

97) „Die ,Volkswirtschaft" verwandelt sich in einen einzigen gewaltigen Trust, dessen Teilhaber die Finanzgruppen und der Staat sind. Solche Bildungen nennen wir staatskapitalistische Trusts." Bucharin, Imperialismus und Weltwirtschaft, a.a. O., S. 131

98) Nikolai Bucharin, Zur Theorie des imperialistischen Staates (1915), in: Die Revolution des Rechts, russisch 1925, zitiert nach: M. Joelson, Monopolistischer Kapitalismus oder „organisierter" Kapitalismus, in: Unter dem Banner des Marxismus, III. Ig., Heft 6, Wien-Berlin 1929, S. 810

99) Hierauf kann nicht im einzelnen eingegangen werden. Vgl. zur Kritik etwa Joelson, a. a. O., und B. Borilin, a. a. O. Für Bucharins methodischen Ansatz ist generell von Bedeutung, daß er die gesellschaftliche Entwicklung von einem, gesellschaftlich-organisatorischen Standpunkt", dem "Standpunkt der gesellschaftlichen Organisationstechnik" her analysiert, was erklärt, daß für Bucharin auch ,alle grundlegenden ,Probleme" der politischen ökonomie" verschwinden, ,sobald wir eine organisierte Wirtschaft betrachten $^{\text {" }}$ (Bucharin, Ökonomik ... , a. a. O., S. 9, S. 64) 
Hier aber ist ein anderer Gesichtspunkt von Bedeutung. Denn Bucharin ver. steht seine Theorie ursprünglich als Modell einer künftigen Entwicklung des Kapitalismus, für die sich aktuell erst eine „Tendenz" zeige: als Modell einer ,Tendenz zur Verwandlung der kapitalistischen Staaten in staatskapitalistische Trusts" (100). Dies wird 1915 immer wieder von Bucharin betont:

\begin{abstract}
„A Ber bis zu einem gewissen Grade und besonders im Vergleich zu der vorliegenden Phase des Kapitalismus haben die wirschaftlich entwickelten Staaten sich in einem bedeutenden Grade bereits dem Punk genöhert, wo man sie... als staatskapitalistische Trusts betrachten kann." $(101)$
\end{abstract}

Diese Aussage deutet zugleich die widerspruichliche Funktion an, die das, ,reine Modell eines Imperialismus bezüglich der realen Entwicklung hat. Denn es ist das logische Modell eines, neuen" Kapitalismus in ,nicht femer Zukunft" wber dessen reale, historische Herausbildung aber keine oder nur widersprüchliche Aussagen möglich sind.

„Die Zukunft gehört also (soweit der Kapitalismus überhaupt bestehen bleibt) Wintschaftsformen, die dem Staatskapitalismus nahestehen." (103)

„Der Zentralisierungsprozeß in seiner kapitalistischen Form stößt hier unvermeidlich auf die ihm gegenüber antagonistische sozialpolitische Tendenz. Er kann seinen logischen Schlußpunkt nicht crreichen; er bricht zusammen und wird erst in einer gereinigten, nicht kapitalistischen Form vollendet." (104)

Auf dieser Stufe der Ausarbeitung der Bucharinschen Imperialismustheorie ist der Staatskapitalismus also lediglich die "letzte denkbare Entwicklungsstufe" (105) des Kapitalismus; eine ,ökonomische" Logik, die in ihrer globalen Durchsetzung allerdings mit ,,sozialpolitischen" Antagonismen kollidiert (106).

Zwei Jahre später aber schreibt Bucharin im, ,Spartak“, dem Organ der Moskauer Leitung der SDAPR:

„In unserem Zeitalter hat sich der Charakter der Konkurrenz zwischen den Kapitalisten wesentlich geändert. Was die modernen kapitalistischen Länder betrifft, so ist sie vollständig auf das Gebiet der auswärtigen Konkurrenz übertragen ... "

100) Bucharin, Imperialismus und Weltwirtschaft, a. a. O., S. 117

$101)$ ebd., S. 131

102) entfält

103) ebd., S. 177

104) ebd., S. 159

105) ebd., S. 133

106) Die methodische Nähe dieser Aussagen etwa $z$ u Hilferdings, ,Generalkartell ${ }^{\text {s }}$ ist gravierend (vgl. Rudolf Hilferding, Das Finanzkapital (1910), Frankfurt 1973, S. 402 f.). Christel Neusi⿺ (Imperialismus und Weltmarktbewegung des Kapitals, Erlangen 1972 , S. $25 \tilde{\mathrm{f}}$.) kritisiert richtig: „Bucharin ... entferne sich mit seinem Begriff der ,Konkurrenz der staatskapitalistischen Trusts auf dem Weltmarkt' so weit von der Rückführung der gesellschaftlichen und politischen Erscheinungen auf die Gesetze der Kapitalbewegung, daß seine Theorie nicht mehr als Fortführung bzw. historische Explikation der Marxschen Theorie betrachtet werden kann." 
„A Auf dem Gebiete der inneren Beziehungen der kapitalistischen Wirtschaft hat der organisicrte monopolistische Kapitalismus die unorganisierten Unternehmen und die ,freie Konkurrenz" abgelöst." (107)

Diese Aussagen aber bleiben nicht auf die Kriegsperiode beschränkt. Auch 1920 - bei der Niederschrift der "Ökonomik der Transformationsperiode ${ }^{66}$.. geht Bucharin von der Existenz einer „Epoche des Staatskapitalismus ${ }^{66}$ (108) aus, die ihn jetzt dazu veranlaßt, ein Modell der, OUbergangsperiode zwischen dem Staatskapitalismus und dern Kommunismus" (109) zu konstruieren.

„Die kapitalistische Volkswirtschaft ist aus einem irrationalen System zu einer rationalen Organisation geworden..." (110)

„... daß die Stabilität der privat-kapitalistischen Systeme innerhalb der Weltwirtschaft, soweit der Krieg zur konkreten Tatsache wurde, ihre Erklärung fand in jener Reorganisation der Produktionsvethältn isse, die die Form des Staatskapitalismus herbeifïhrte. "(111)

usw., usw. In der Entfaltung der Bucharinschen Theorie läßt sich so aufzeigen, daßs eine urspringlich als Tendenz bezeichnete Entwicklung - die in methodischer Hin.. sicht bereits eine ,falsche Verallgemeinerung" darstellte - schließlich zur Behauptung der Existenz eines Staatskapitalismus führt.

In diesem Zusammenhang ist auch ein Hinweis Bucharins interessant, den er später in einem Artikel in der "Prawda" gibt. Denn hier unterscheidet er zwischen zwei ,Zyklen" der Entwicklung des Staatskapitalismus: einem ersten, den er als ,geplante Wirtschaft der belagerten kapitalistischen Festung (,Staatskapitalismis der Kriegsperiode $)^{66}$ bezeichnet und einem ,zweiten Zyklus"6, der ,vom ersten, Kriegszyklus, gänzlich verschieden ist." Dieser ,Zweite Zyklus" sei ein ,Staatskapitalismus, der sich als ,normales" kapitalistisches System entwickelt." (112). Bei Bucharin stellt sich so sehr plastisch dar, wie die Kriegswirtschaft den Übergang von einem (in dem oben begründe ten beschränkten Sinn) „prä7isen“ Begriff zur Theorie des Staatskapitalismus markiert.

Aber diese Verallgemeinerung zur Theorie des Staatskapitalismus vollzieh sich auch noch in einem anderen Sinne, da sich unter dem Eindruck der Kriegswirtschaft eine allgemeine Assimilation an die Begrifflichkeit des Staatskapitalismus innerhalb der Arbeiterbewegung durchsetzt, allerdings bei sehr unterschiedlichen

107) Bucharin, Der Krieg und der revolutionäre Sozialismus, in: Spartak Nir. 1; ders, Zur Revision des Parteiprogramms, in: Spartak Nr.4, zitiert nach: Joelson, a. a. O., S. 811 f.

108) ders., Ökonomik..., a. a. O., S. 84

109) ebd., \$. 119

110) ebd., S. 16. Diese ,Rationalität" fuihrt schließlich sogar dazu, daß im Staatskopitalismus die Produktion von Mehrwert tendenziell verschwindet: „Beim Staatskapitalismus ist der Produktionsprozeß ein Prozeß der Produktion von Mehrwert . . mit der Tendenz, diesen Wert in Mehrprodukt zu verwandeln. ${ }^{\text {se }}$ (ebd., S. 116)

11) ebd., \$. 160

112) ders., Die Theorie der organisierten Unwirtschaftlichkeit, Prawda vom 30. Juni 1929, untet dem Titel, Organized Mismanagement in Modern Society ${ }^{65}$ teilweise in: A Handbook of Socialist Thought, ed. by Irving Howe, London 1972, S. $394 \mathrm{ff}$, hier: S. 397. Vgl. auch ders., Ókonomik..., a. a. O., S. 113, wo bereits von einem, finanzkapitalistischen Staatskapitalismus der Kriegsperiode" die Rede ist. 
politischen Schlußfolgerungen. (Das kennzeichnet auch bis heute die Heterogenität dieser Theorie, )

Als Beispiel dafur kann etwa Karl Renner genommen werden, der aus der Erscheinung der Kriegswirtschaft eine notwendige "Ergänzung " der ,offenen" Probleme der Marxschen Kapitalismusanalyse begründet.

„Dic Epoche des individuellen Privatunternehmers, der sich in volier Freiheit des Wettbewerbs durchsetzt, ist schon länger dahin, als wir glauben. Dabei wollen wir nicht etwa die Tatsache so zahlreicher Verstaatlichungen ins Feld führen, die an sich den Staat nur zum Privateigentümer machen und an dem sozialen Gefüge nichts oder nur wenig ändem. Es handelt sich um die Durchdringung der Privatwirtschaft selbst bis in inr Zellgewebe durch die Staatlichkeit, also nicht nur Verstaatlichung einiger Betriebe, sondern um die Durchsetzung der gesamten Privatwirtschaft durch deren gewollte und bewußte Bestimmung und Leitung, also gerade durch das, was Karl Marx'System logisch und praktisch ausgeschlossen hat. Nennen wir es die ,Durchstaatlichung der Ökonomie"..."(113)

Von hier aus wird dann einerseits ,mit dem durch die Kriegswirtschaft geschärften Auge" (114) die Geschichte der letzten 40 Jahre des Kapitalismus als stufenweise Steigerung dieser „Durchstaatlichung der Ökonomie" umgeschrieben, andererseits auch die künftige Entwicklungsform des Kapitalismus und die Taktik der Sozialdemokratie daraus begründet.

Renner unterscheidet zwischen einer „Niederschutzepoche“(1878-1890), einer „Epoche organisierter Privatwirtschaft", einer „Epoche des imperialistischen Hochschutzes" (115), der sich eine, ,staatswirtschaftliche Epoche" anschließe:

„Es ist ... eine staatswirtschaftliche Epoche, in die wir eingetreten sind, in der neben der hoheitlichen und richterlichen Tätigkeit der Staat die Aufgaben eines Wirtschaftsamtes übernommen hat, all das durchaus auf dem Boden der kapitalistischen Wirtschaftsordnung. Wenn man den Ausgangs- und Endpunkt der Reihe gegenüberstellen will, kann man sagen: Privatkapitalismus hat sich in Staatskapitalismus gewandelt oder steht auf dem Wege dazu." (116)

Das Spezifikum des Staatskapitalismus besteht nach Renner in dem besonderen Verhälṫnis von Ökonomie und Politik, Staat und Kapital:

,Die Ökonomie dient immer ausschließlicher der Kapitalistenklasse, der Staat immer vorwiegender dem Proletariat." (117)

Das eröffnet die Möglichkeit, mittels des Staates , das Kapital aus seiner Herren- in die Dienerrolle zurück(zu)drängen ${ }^{66}(118)$, was für den Kampf des Proletariats bedeutet,

113) Karl Renner, Marxismus, Krieg und Internationale - Kritische Studien über offene Probleme des wissenschaftlichen und des praktischen Sozialismus in und nach dem Weltkrieg, Stuttgart 1917, S. 12

114) ebd., \$. 13

115) ebd., S. $14 \mathrm{ff}$.

116) ebd., S. 19

$117)$ ebd., S. 27

$118)$ ebd. S. 19 
„daß das Schicksal des Proletariats eines Landes mit dem Geschick des Staates zusammenfällt. “(119)

Und der Schlußsatz dieser Theorie lautet dann, daß

„... der Grad der Stautsnähe und nicht der Grad der Staatsferne ein Merkmal der Klassenreife" $(120)$

sei. Wird die „Staatsnähe ${ }^{66}$ als Ausdruck von Klassenbewußtsein zum Hebel des Aufbaus des Sozialismus, ist diese selbst aber erst mit der zunehmenden Tendenz der „Durchstaatlichung der Ökonomie" möglich, so wird der Staatskapitalismus zur notwendigen Entwicklungsstufe des Kapitalismus, der diesen jedoch zugleich gegenüber einer Transformation zum Sozialismus immunisiert, indem er ein Begründungsmuster liefert, aus dem wechselnd die noch bestehende objektive oder subjektive "Unreife" zur Revolution interpretiert werden kann. Die Theorie der ,Staatsnähe" und der "Durchstaatlichung der Ökonomie", die innerhalb der Sozialdemokratie natürlich nicht auf $\mathbb{K}$ arl Renner beschränkt war (121), hat dann auch als Rationalisierung jener schizophrenen Praxis der Nachkriegszeit gedient, durch Beteiligung am Wiederaufbau des Kapitalismus zum Sozialismus zu gelangen.

Diese knappen Hinweise, beschränkt auf die theoretischen Ansätze bei Bucharin und Renner, mögen ausreichen, um die These zu illustrieren, die für die Frage der Übertragung der Theorie des Staatskapitalismus auf die Übergangsgesellschaften von außerordentlicher Bedeutung ist: daß nämlich unter dem Eindruck der Kriegswirtschaft eine Theorie des Staatskapitalismus entsteht und verallgemeinert wird. Verallgemeinert zum einen in dem Sinne, daß die Kriegswirtschaft als Modell der normalen, künftigen Entwicklung des Kapitalismus interpretiert wird; zum anderen in dem Sinne, daß sich diese Interpretation auch quer durch die internationale Arbeiterbewegung verallgemeinert, als allgemeines falsches Bewußtsein, das aber dennoch unierschiedliche politische Schlußfolgerungen und Praxisformen zuläßt (122).

An zwei weiteren, sehr unterschiedlichen Beispielen aus der Zeit nach dem I. Weltkrieg mag in etwa sichtbar werden, welches Ausmaß dieses allgemeine, falsche Bewußtsein, das sich in der Theorie des Staatskapitalismus manifestiert, angenommen hat.

119) ebd., S. 378

120) ebd., S. 379

121) Auch Otto Bauer (Bolschewismus oder Sozialdemokratie, Wien 1920, insb. S. $91 \mathrm{ff.}$ ) datiert seit der Kriegswirtschaft ein "Zeitalter des Staatskapitalismus". A hnlich auch in Kautskys ,Sozialdemokratische Bemerkungen zur Übergangswirtschaft", Leipzig 1918 , S. $28 \mathrm{ff}$.

122) Die Interpretation der Theorie des Staatskapitalismus als allgemeines, falsches Bewußtsein meint nicht eine arrogante Qualifizierung vom Standpunkt des eigenen "richtigen" Bewußtseins. Aber man muß verstehen, welche A uswirkungen das ,Novum " Kriegswirtschaft auf die Arbeiterbewegung gehabt hat. Es ist evtl. yergleichbar mit den Interpretationen der ,Rekonstruktionsperiode" nach dem 2. Weltkrieg, die erst durch die objektive Entwicklung des Kapitalismus destruiert wurden. 
1921 erscheint eine programmatische Schrift aus den Reihen der KPD (123), die ein Kapitel „Die Angst vor dem Staatskapitalismus" enthält. Hierin wird die Intwicklung Deutschlands seit 1918 bilanziert; eine Entwicklung, die durch die Koalition der Mehrheitssozialdemokratie mit der Bourgeoisie zu einem wirtschaftichen Chaos gefüht und das Ergebnis hervorgebracht hat, daß statt Sozialisierung etzt die „Stinnesierung" (124) auf der Tagesordnung steht. Die Alternative:

„Verzichtet die demokratische Republik darauf, den Ausverkauf Deutschlands durch Tausende und Abertausende von Einzelschicbern einzudämmen, indem sie die Industrie syndiziert und sie unter die Kontrolle des Staates nimmt, so werden die großen deutschen Kartelle diese Aufgabe durchfuhren."(125)

Und in diesem Kontext der Alternative von, Stinnesierung oder verstärkter Einfluß des Staates werden dann die Einwände gegen die vorgeschlagene Politik aus den eigenen Reihen unter dem Titel "Die Angst vor dem Staatskapitalismus" diskutiert.

„Der erste Einwand bezieht sich auf den Zustand, den wir im besten Fall auf dem hier geschilderten Weg erreichen können; es ist nicht der Kommunismus, sondern der Staatskapitalismus der so erreicht werden könnte ... "(126)

Dem wird entgegnet, daß zu einem Zeitpunkt, wo das Privatkapital die kriegswirtschaftlichen Maßnahmen zu liquidieren sucht, „die Forderung der Teilnahme des Straates an der Industrie den schärfsten Kampf gegen die Bourgeoisie" bedeute und daher gerade ,der Weg zum ,Staatskapitalismus' der Weg des revolutionären Kampfes" (127) sei.

Ein zweiter Einwand bezieht sich darauf, daß durch diese Forderung einer , leitende(n) Teilnahme des Staates an der Industrie"(128) auch von der KPD zugegeben werde,

,daß wir erst durch eine Epoche des Staatskapitalismus hindurch müssen, bevor die Arbeiterklasse siegen kann." (129)

Dieser Text erscheint mir insofern interessant, weil er sichtbar macht, wie die Diskussion über die unmittelbare politische Praxis auch innerhalb einer Partei, die sich im Gegensatz - und gerade deswegen - zur Staatsbejahung der Mehrheitssozialdemokratie definiert, von den durch die Kriegswirtschaft produzierten ideologischen Theorie-Formen tangiert wird.

Dieses falsche Bewußstsein blieb allerdings nicht nur auf die Kriegsperiode und die unmittelbare Nachkriegszeit beschränkt. Als unter dem Eindruck der Weltwirtschaftskrise und den dadurch bedingten Maßnahmen des Staates innerhalb der Ar-

123) Karl Bremer, Der nahende Zusammenbruch der deutschen Bourgeoisie und die KPD, Hamburg 1921

124) ebd., S. 10

125) ebd., $\$$. 9. Zu den konkreten Vorschlägen siehe insb. $\$ 19 \mathrm{f}$.

126) ebd., S. 22

127) ebd., S. 23 f.

128) ebd., S. 19

129) ebd., S. 24 
beiterbewegung nach den Perspektiven des Kapitalismus gefragt wird, tauchen sie erneut auf - Otto Rühte mag als ein Beispiel dafür dienen. Für ihn sind die Bankrotte verschiedener Konzerne (êwa Karstadt, Linoleum-Konzern) und die Zusammenbrüche großer Banken (wie der Österreichischen Kredit-Anstalt und der Danatbank in Berlin) im Gefolge der Weltwirtschaftskrise das Zeichen dafür, daß ,der Privatka. pitalismus in einer Weltkrise untergeht" (130). In den theoretischen Diskussionen spiegele sich das als Wiederauftauchen von Modellen einer ,Art Kriegsplanwirtschaft ${ }^{6}$ (131) nach dem Vorbild des 1 . Weltkrieges wider. Alle diese Planwirtschaftstheorien blieben allerdings spekulativ, so argumentiert Rühe, wenn sie nicht von einer Analyse der realen Tendenzen ausgingen, die bereits Keimformen dieser „Planwirtschaft ${ }^{\text {ts }}$ sind. Diese realen Tendenzen seien in zwei Momenten gegeben:

„Das eine Monent ist gegeben in der Tendenz zu immer höherer Konzentration der Wirtschaftskräfte und Wirtschaftsformen",

wobei das

"denkbar letzte Resultat dieses Prozesses... eine Art Universaitrust, ein Generalkartell (sei) ... Das zweite Moment der Wirtschaftsverfassung von heute, das auf eine Staatspianwirtschaft hinweist, entspringt der Subventionspolitik, die in der Phase des Spätkapitalismus, besonders in dessen letzter Niedergangskurve, aus dem Bilde der Wirtschaftskonstitution nicht wegzudenken ist." (132)

Da die zunehmende Konzentration der Kapitale zu scharfen Krisen des gesellschaftlichen Reproduktionsprozesses führt, macht sie die staatlichen Subventionen zur Stiitzung des Privatkapitals notwendig.

„Das ist der erste Schritt auf dem Wege zum Staatskapitalismus. Verwaitung und Geschäft gehen eine Fusion ein. Staatliche und kapitalistische Interessen verschmelzen miteinander. Staatsfinanzen und Erwerbswirtschaft finden sich zu ihrer Einheit. ${ }^{66}$ (133)

Dabei gebe es zwei Möglichkeiten: einmal die, ,daß sich die Privatwirtschaft vom Staat usurpieren läß $\mathrm{t}^{\text {t6 }}$ oder aber ihr Gegenteil: „der Staat wird vom Privatkapital usurpiert" (134), wobei sich in Deutschland die letztere Möglichkeit entwickele. Für die Bedingungen kapitalistischer Reproduktion aber sei das letztlich gleichgültig. ,So oder so - der Kapitalismus hat auch in der Form des Staatskapitalismus keine aussichtsreichen Chancen, sein Dasein für lange Zeit fortzusetzen" (135). Die einzige „Rettung" eines zunächst national organisierten Staatskapitalismus sei nunmehr das "Aufgehen im Generaltrust der Weltwirtschaft", die Entwicklung zum „Weltstaatskapitalismus" ${ }^{6}$, von dem man sich dann erneut erhoffen mag, „,dem kapi-

130) Carl Steuermann (Pseudonym fur Otto Ruhle), Weltwirtschaftskrise - Weltwende. Kurs auf Staatskapitalismus, Berlin 1931, \$. 154

131) ebd., S. 158

132) ebd., \$. 179f.

133) ebd., S. 181

134) ebd., S. 231 i.

135) ebd., \$. 244 
talistischen System die denkbar längste Lebensdauer zu sichern" (136). Aber auch damit sei keine Behebung der Krise des Kapitalismus möglich, weil trotz Rationalisierung der Produktion ein Problem bestehen bleibe: das ,Absatzproblem", das unter kapitalistischen Bedingungen unlösbar ist (137). Insofern stelle auch der Staatskapitalismus nur eine Notlösung dar und werde daher letztlich durch Revolutionen und Kriege in eine Gesellschaft transformiert, in der „Einheit des Besitzes, der Produktion und der Bedarfsdeckung" (138) hergestellt sein wird.

Insgesamt bestätigen diese Beispiele quer durch die verschiedenen Fraktionen der Arbeiterbewegung, wie durch die objektiven Veränderungen des Kapitalismus bestimmte ideologische Theorie-Formen erzeugt werden, in denen sich auch eine revolutionäre, den Kapitalismus negierende Praxis theoretisch darstellt. Die Entwicklung des Kapitalismus vor und während des I. Weltkrieges hat eine solche ideologische Theorie-Form produziert: die Theorie des, Staatskapitalismus“".

Und dieses Ergebnis ist der Schluissel zum Verständnis dafür, daß die Theorie des ,Staatskapitalismus"6 auf die Übergangsgesellschaften, d. h. hier zunächst die Sowjetunion, übertragen wurde, wobei Übertragung ein doppeltes meint: einerseits, daß die Revolutionäre, die den russischen Kapitalismus gestürt haben, selbst in dieser praktischen Negation des Kapitalismus sich noch in diesen ideologischen Theorie-Formen artikuliert haben; andererseits, daß auch jene, die die russische Revolution damals kritisiert und bekämpft haben, ihre Kritik ebenfalls in diesen Formen vollzogen (139). Diese These würde dann auch erklären, warum die Theorie des Staatskapitalismus für die Revolutionäre in China und Cuba keine Rolle gespielt hat, lediglich in der russischen Revolution (140).

\section{Die Theorie des Staatskapitalismus als Theorie der Übergangsgesellschaft}

\subsection{Staatskapitalismus und Aufbau des Sozialismus - Die Theorie des Staatskapita- lismus in der russischen Revolution (Lenin's Konzept des Staatskapitalismus)}

Der objektive und zeitliche $\mathbb{Z}$ usammenhang von imperialistischer Kriegswirtschaft und russischer Revolution haben bewirkt, daß sich auch die russischen Revolutionäre in den durch die Kriegswirtschaft produzierten ideologischen Theorie-Formen artikuliert haben (141). Das schien bereits in der Analyse des Kapitalismus bei

136) ebd., S. 246

137) ebd., S. 250

138) ebd., \$. 254

139) Das gilt meines Erachtens fur die damalige sozialdemokratische und anarcho-syndikalistische Kritik der russischen Revolution, dic in Teil II, 2.1. und Teil II, 2.2. dargestellt wird.

140) Hierauf wird am Ende des Teils II.1 nochmals eingegangen.

141) Das erklärt sich dadurch, daß die Bolschewiki gerade die Entwicklung des deutschen Kapitalismus analysiert haben, da sie die russische Revolution nur im Kontext einer westeuropäischen Revolution gedacht haben, für letztere aber der Sturz des deutschen Kapitalismus von entscheidender Bedeutung war. 
Varga und Bucharin durch; unzählige weitere Beispiele ließen sich hierfür anführen (142). Jetzt soll gezeigt werden, wie auch die Theorie-Form der eigenen revolutionären Praxis an diese ideologische Begrifflichkeit anknüpfte, wie also - um es auf der begrifflichen Ebene auszudricken - der Aufbau des Sozialismus am ,Staatskapitalismus" orientiert wurde.

Das impliziert nun aber eine Untersuchung in zweierlei Richtung: einmal den Nachweis, daß die Theorie-Form der eigenen Praxis sich an dem ideologischen Begriff des „Staatskapitalismus" orientierte, zum anderen aber, welche - und auch welche unterschiedliche - Praxisform zur Überwindung der realen Schwierigkeiten der Transformation zum Sozialismus in ihr gedacht wurde. Nur so können einseitige Interpretationen vermieden werden, die darauf hinauslaufen, entweder die Begrifflichkeit des Staatskapitalismus selbst unkritisch zu übernehmen, eben weil diese nicht auf ihre historische Bedingtheit hinterfragt wird (143), oder aber aus einer ,falschen ${ }^{66}$ Begrifflichkeit auch unmittelbar auf ,falsche ${ }^{66}$ Praxisformen zu schließen.

Für die Entwicklung dieser Problematik sind die Ausführungen Lenin's am geeignetesten, weil sie sich selbst gegen zwei andere Interpretationen absetzen: die der "linken Kommunisten", die im Frühjahr 1918 aus bestimmten Maßnahmen wie zentralistische Leitung der Industrie, materielle Privilegierung der "Spezialister ${ }^{\text {i6 }}$ etc. eine „Evolution zum Staatskapitalismus" folgerten (145), damit also den Begriff des Staatskapitalismus auf das gesamte sozio-ökonomische System bezogen; zum anderen gegen die Position Bucharin's, der einen Staatskapitalismus in der Sowjetunion prinzipiell ausschloß. Da die Position der ,linken Kommunisten "6 auf ähnliche Probleme verweist, wie sie später noch bei den einzelnen Varianten eines Nachweises der Existenz eines Staatskapitalismus in der Sowjetunion auftauchen, will ich mich auf Bucharin beschränken und daraus dann die Verwendung des Staatskapitalismus-Begriffs bei Lenin entwickeln.

Für Bucharin (wie auch für Lenin) impliziert jede Aussage über den ,Staatskapitalismus" zunächst einmal einen revolutionstheoretischen Aspekt, nämlich den,

142) Zwar keine der Bucharinschen Theorie des Staatskapitalismus vergleichbare Theorie, dennoch aber eine Verwendung dieses ideologischen Terminus findet sich in zahlreichen Texten. Vgl. für viele andere etwa I. Larin/L. Kritzmann, Wirtschaftsleben und wirtschaftlicher Aufbau in Sowjetrußland 1917-1920, Hamburg 1921, S. 148; E. Preobrazenskij, Die Neue Ökonomik, Westberlin 1971, S. 23; Leo Trotzki, The class nature of the soviet state, London 1968, S.18. Zu entsprechenden Außerungen Lenins vgl. Autorenkollektiv Projekt Klassenanalyse, Leninismus - neue Stufe des wissenschaftlichen Sozialismus, Westberlin 1972, S. $372 \mathrm{f}$; außerdem die dort nicht aufgeführten Stellen aus W.I. Lenin, Krieg und Revolution (in: Werke Band 24, Berlin/DDR 1959, S. 395 ff.) und ders., UUber die revolutionäre Phrase (Werke Band 27, Berlin/DDR 1970, S.4)

143) Das ist etwa der Fall bei Bernd Rabehl, Die marxistische Theorie der Transformationsgesellschaft am Beispiel der Entwicklung der russischen Revolution, in: Gesellschaftsstrukturen ..., a. a. O., insb. S. $252 \mathrm{ff}$.

144) enträllt

145) Mit der Position der, ,inken Kommunisten" setzt sich Lenin z. B. in seiner Schrift ,"Uber ,linke" Kinderei und über Kleinbürgerlichkeit", in: Ausgewählte Werke Band III, Berlin/DDR 1970, S. 786 ff. auseinander. Die Schriften Lenins werden im folgenden soweit möglich nach den „Ausgewählten Werken " (abgekürzt: AW $\mathbb{1}$-lll) zitiert, die übrigen nach den Einzelbänden der Dietz-Ausgabe, Berlin/DDR 1959-1971 (abgekürt: LW) 
daß ,das Vorhandensein eines Systems des Staatskapitalismus zu einer bestimmten Periode ... ein empirischer Beweis für die ,Möglichkeit' des kommunistischen Aufbaus (ist) ${ }^{6}(146)$; eine objektive Möglichkeit, die demnach auch je nach dessen Entfal tungsgrad differiert:

„Je verhältnismäßig größer die Konzentrier theit des Proletariats ist, umso höher steht der Typus der kommunistischen Revolution, umso schwieriger ist es zu siegen, aber umso leichter zu bauen." (147)

Beim Aufbau des Sozialismus im ökonomisch rückständigen Land stellt sich nun nach Bucharin ein formal ähnliches Problem wie im Staatskapitalismus, obwohl andererseits die gesellschaftliche Struktur dieses Landes durch die Machteroberung des Proletariats bereits prinzipiell von der des Staatskapitalismus verschieden ist.

„In diesem Rahmen und auf dieser Grundlage (unter den Bedingungen der Diktatur des Proletariats - d. Verf.) sind die Aufgaben, vor denen das Proletariat steht, im großen und ganzen, formal, $d . h$. unabhängig von dem sozialen Inhait des Prozesses, dieselben wie auch für die Bourgeoisie bei der erweiterten negativen Reproduktion ... " (148),

der Transformationsprozeß also wesentlich ein ,Organisationsproblem":

„Der Sozialismus, als organisiertes System wird von dem Proletariat, als dem organisierten Kollektivsubjekt, gebaut. " (149)

Erst die Reduzierung des Begriffs des Staatskapitalismus auf ein formales Organisationsprinzip, eine ,gesellschaftliche Organisationstechnik“(150), unabhängig von den spezifischen gesellschaftlichen Produktionsverhältnissen erlaubt diese Analogie, die selbst keine positive Charakteristik der sozio-ökonomischen Verhältnisse im Übergang vom Kapitalismus zum Sozialismus mehr enthalten kann. Bucharin muß sich daher auf eine negative, prinzipielle Abgrenzung beschränken:

„Kurzum, die funktioneile Gegensätzlichkeit der formal ähnlichen Erscheinungen wird hier total bestimmt durch eine funktionelle Gegensätzlichkeit der Organisationssysteme, durch deren entgegengesetzte Klassencharakteristik" (152),

woraus Bucharin begründet,

,daß von keinerlei ,Staatskapitalismus" die Rede sein kann bei der Diktatur des Proletariats, die eine solche Möglichkeit prinzipiell ausschließt." (153)

146) Bucharin, Ökonomik ..., a. a. O., \$. 61

147) ebd., S. $161 \mathrm{f}$. Analog Lenin bereits auf dem VII. Parteitag der KPR (B) im März 1918. Vgl. AW III, S. 659

148) Bucharin, Ökonomik ..., a. a. O., S.64. In dieses Zitat geht eine formale Analogie zwischen dem ,Staatskapitalismus der Kriegsperiode ${ }^{s 6}$ (,,erweitere negative Reproduktion $^{6)}$ ) und dem ,Kriegskommunismus" ein, den Bucharin ja in seiner, ,Ókonomik" theoretisiert.

149) ebd., S. 65

150) ebd., S. 64

151) entfällt

152) ebd., S. 118

153) ebd., S. 115. Bucharin wendet sich damit u. a.gegen Äußerungen von Zyperowitsch und 
Bucharin versucht schließlich beide Aspekte - die formale Analogie und die prinzipielle Gegensätzlichkeit von Staatskapitalismus und Sozialismus - in einem Ausdruck zu fassen, dem der ,dialektischen Negation", wobei nicht klar wird, worin denn die „Dialektik“ besteht, eben weil hier formale Analogien mit gesellschaftlichen Verhältnissen vermengt werden.

„Es ist volikommen klar, daß die nächste Epoche die Epoche der Dikatur des Proletariats sein muß, die formal Ähnlichkeit mit der Epoche der Diktatur der Bourgeoisie haben wird, d. h. der umgestülpte Staatskapitalismus, seine dialektische Umkehrung in seinen eigenen Gegensatz sein wird." (154)

Bucharin bestätigt im Grunde selbst, wie sehr er an den ideologischen, durch die Entwicklung des Kapitalismus produzierten Begriffen orientiert bleibt, die bei ihm zudem „organisationstechnisch ${ }^{66}$ gefaßt werden, wenn er schreibt:

„Das System der sozialistischen Diktatur, die man als „Staatssozialismus' bezeichnen könnte, wenn die letztere Bezeichnung nicht durch ihren üblichen Gebrauch kompromittiert wäre, ist die dialektische Negation, das Gegenteil des Staatskapitalismus.“ (155)

Der Bucharin'sche Standpunkt der prinzipiellen Unmöglichkeit eines „Staatskapitalismus $^{66}$ in der Sowjetunion bleibt nicht nur fixiert auf die Verwendung dieses Begriffs auf die Gesamtheit eines sozio-ökonomischen Systems, sie impliziert auch eine zu vereinfachte Praxisform der sozialistischen Transformation, die wesentliche Widersprüche negiert, die aus den materiellen Bedingungen der ökonomischen Rückständigkeit resultieren.

Und gerade hier, mit dieser praktischen Intention, setzt die Kritik Lenin's an.

„... gerade jetzt sagt Gen. Bucharin mit Unrecht, unter der Sowjetmacht könne es keinen Staatskapitalismus geben. ${ }^{\text {" }}$

\section{Lenin setzt dem entgegen:}

„Jetzt können wir nicht umhin, die Frage des Staatskapitalismus und des Sozialismus zu stellen, die Frage, wie wir in der Übergangsepoche zu handeln haben - hier existieren unter der Sowjetmacht ein Stück Kapitalismus und ein Stück Sozialismus nebeneinander. Diese Frage will Gen. Bucharin nicht begreifen." (156)

Diesen Kern seiner Kritik formuliert Lenin auch in seiner Notiz an Bucharin:

Bojarkow, die den „Kriegskommunismus" als eine „Stufe des Staatskapitalismus ${ }^{65}$ interpretierten.

154) ebd., S. 69; analog S.78, \$. 89

155) ebd., S.115.f. Auch später, als Bucharin bereits zum Theoretiker des, ,Anti-Trotzkismus $^{66}$ geworden war, schreibt er in seiner Kritik an Preobrazenskijs, Neue Ökonomik ${ }^{46}$,

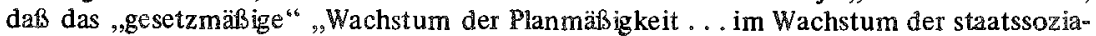
listischen Elemente der Wirtschaft" seine Basis habe (Bucharin, Zur Frage der Gesetzmäßigkeiten der Ûbergangsperiode, in: Internationale Presse-Korrespondenz Nr. 98, Berlin 1926, S. 1595)

156) W. I. Lenin, Tagung des Gesamtrussischen Zentralexekutivkomitees, 29.4.1918, in: LW 27, S. $297 \mathrm{f}$. 
Mieraus geht einerseits hervor, daf Lenin es ablehnt, von einer, ,prinzipiellen Unmöglichkeit ${ }^{\text {t }}$ eines Staatskapitalismus zu sprechen, wie auch diesen Begriff zur Charakterisierung der sowjetischen Gesellschaft insgesamt zu verwenden. Andererseits, daß er mit seiner Kritik - und damit, wie er den Begriff selbst verwendet intendiert, sowohl die Schwierigkeiten der sozialistischen Transformation unter den Bedingungen der Rückständigkeit Rußlands, die eben noch teilweise kapitalistische Verhältnisse bedingt, zu kennzeichnen, als auch die Mittel und die Tendenz zur Lösung dieser Widersprüche aufzuzeigen. Das ist der eminent praxisorientierte Sinn seiner Formulierung "Kapitalismus + Sozialismus" ${ }^{46}$, und auch der gleichbleibende allgemeinste Ausdruck des Staatskapitalismus-Begriffs. Es wird allerdings noch zu zeigen sein, wie unterschiedlich Lenin selbst diesen Begriff verwendet.

Der Begriff des, Staatskapitalismus" ${ }^{6}$ sowohl wie ihn Lenin 1916/17 gelegentlich zur Kennzeichnung der spezifischen Entwicklungsstufe des Kapitalismus (158), wie auch 1918 und 1921 bezüglich der sozialistischen Transformation in Rußland gebraucht - bringt wesentlich eines zum Ausdruck: den Entwicklungsgrad der Vergesellschaftung der Arbeit (159), dessen materielle Bedingungen durch die Entwicklung des Kapitalismus bereits hergestellt wurden, im ökonomisch rückständigen Rußland aber noch weitgehend fehlen, hier die isolierte Arbeit noch dominiert. Deutschland und Rußland sind für Lenin die ,zwei getrennte(n) Hälften des Sozialismussis sie

„yerkörpern 1918 am anschaulichsten die materielle Verwirklichung einerseits der ökonomischen produktionstechnischen, sozialwirtschaftlichen Bedingungen und andererseits der politischen Bedingungen für den Sozjalismus" (160),

zwei "Hälften", die Lenin - unter der Voraussetzung einer baldigen Revolution in Deutschland - durch den "Kriegskommunismus ${ }^{6}$ und dessen Orientierung auf die Schaffung einer Großproduktion in Rußland zu vereinigen hofft.

„Solange in Deutschland die Revolution noch mit ihrer ,Geburt" säumt, ist es unsere Aufgabe, vom Staatskapitalismus der Deutschen zu lemen, ihn mit aller Kraft zu übernehmen, keine diktatorischen Methoden zu scheuen. ... In Rußland überwiegt jetzt gerade der kleinbürgerliche Kapitalismus, von dem sowohl zum staatlichen Großkapitalismus als auch zum Sozialismus ein und derselbe Weg führt, der Weg über ein und dieselbe Zwischenstation, die, allgemeine Rechnangsführung und Kontrolle über die Erzeugung und Verteilung der Produkte heifft." (161)

157) ders., Notiz für N. I. Bucharin, März-A pril 1921, in: LW 36, S. 529

158) Vgl. Anm. 142

159) Vgl. auch etwa: Der Imperialismus als höchstes Stadium des Kapitalismus, in: AW I, S. 784, S. 872; VI. Gesamtrussische Konferenz der SDAPR (B), in: AWI, S. 103 f.; Die drohende Katastrophe und wie man sie bekämpien soll, in: AWII, S. 300; Uber linke Kinderei..., a. a. O., S. 790 f. Lenin kritisiert gerade an Bucharin, daß dieser unter Vergesellschaftung nur die Entwicklung der organisatorischen Formen des Kapitals verstehe. Vgl. Borilin, a. a. O., S. 844

160) Lenin, Uber ,linke ${ }^{6}$ Kinderei ..., a. a. O., \$.791

161) ebd., S.791 f. 
Damit warnt Lenin vor einer blor abstrakten Gegentiberstellung von Kapitalismus und Sozialismus, die von den konkreten Bedingungen des Transformationsprozesses abstrahiert und, die konkreter Formen und Sturen dieses Ubergangs (162) nicht erfaßt. Gegenüber der , prinzipielien Negation ${ }^{6}$ müsse ausgesprocher werden,

,daß zwischen dem Sozialismus und Kapitalismus eine lange, mehr oder weniger schwierige Ubergangsperiode der Diktatir. des Proletaria ts legt. ${ }^{\text {s* }}$ (163)

Der Begriff des Staatskapitalismus, der bereits bezogen auf die Entwicklung der kapitalistischen Länder die Redingungen eines Übergangs zu einer höheren Produktionsweise zum Ausdruck brachte (164), bezeichnet nun auch beziglich der sowjeti-

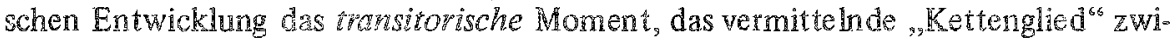
schen kleinbürgerlichem Rapitalismus und ,sozialistischer" Grobproduktion, im Prozeß der russischen Revolution, den Übergang von den Konfiskationen ... zur Vergesellschaftung. ${ }^{66}$ (165) Das entscheidende ${ }_{9}$ Kettenglied ${ }^{64}$ für den Aufban des Sozialismus sieht Lenin im Fruhjahr 1918 - in der durch den Brester Frieden geschaffenen zeitweiligen ,A Atempause " und auf dem Hintergrund einer durch $\mathbb{K}$ rieg und Revolution zerstörten Wirtschaft - im Aufbau einer industriellen Großproduktion:

,Nur diese matwiellen Bedingungen, die Bedingungen der maschinellen Großindustrie gigantischer Unternehmungen, die für Dutzende Millionen arbeiten, nur sie sind die Crundlage des Sozialismus, und diese Sache in einem kleinbürgerlichen, bäuerlichen Land zu erlemen ist schwer, aber möglich." (166)

Durch Übernahme der „Apparate der Rechnungsfïhrung “ (167), der bereits durch den Kapitalismus produzierten ,organisatorischen Form der Arbeit ${ }^{\text {"s }}$ (168), könne „,die kleinbürgerliche Anarchie ... (der) Houptfeind des Sozialismus" (169) zurückgedrängt werden; ohne diese "Entwicklung des Staatskapitalismus" dagegen sei in einem Land wie Rußland, ,kein Sozialismus möglich" ${ }^{66}(170)$.

"In einem Land wie Rußland" heißt aber 1918 bereits, daß Machtorgane des Proletariats und der Bauernklasse existieren.

„Ohne die Sowjets wäre diese Aufgabe (Rechnungsfähigkeit und Kontrolle - d. Verf.) zumindest für Rußland, unlösbar." (171)

,Rechnungsfuhrung und Kontrolle, wenn sie von den Sowjets ... oder ... im Auftrag dieser Staatsmacht ausgeibt wid, ... darin besteht das Wesen der sozialistischen Umgestaltung, nach-

162) ebd., S. 792

163) ders., Bericht über die Tätigkeit des Rats der Volkskommissare auf dem III. Sowjetkongreß, in: AW II, S. 615

164) Lenin spricht in diesem Sinne auch von einem, ,Ubergangskapitalismus ${ }^{60}$, in: Der Irmperialismus ..., a. a. O., S. 872

165) ders., Über ,linke Kinderei ..., a. a. 0., S. 785

166) ders., Tagung des Gesamtrussischen Zentralexekutivkomitees, a. a. O., S. 288

167) ders., Werden die Bolschewiki die Staatsmacht behaupten?, in: AWII, S. 461

168) ebd., \$. 465

169) ders., Über ,linke‘ Kinderei . . , a. a. O., S. 786

170) ders., Tagung des Gesamtrussischen Zentralexekutivkomitees, a. a, O., S.287

171) ders., Werden die Bolschewiki ..., a.a. O., $\$ .461$ 
dem die politische Herrschaft des Proletariats begründet und gesichert ist." (172)

So kennzeichnet der Begriff des Staatskapitalismus im Lenin'schen Gebrauch drei Momente: die Notwendigkeit einer Übergangsperiode vom Kapitalismus zum Sozialismus, deren Tendenz durch eine Steigerung der Produktivkräfte (hier noch wesentlich Schaffung einer Großproduktion) unter der Bedingung einer Sowjetdemokratie bestimmt wird. In diesem Sinn ist, ,der Staatskapitalismus ein Schritt zum Sozialismus ${ }^{64}$ (173).

Ist so zunächst die praktische Intention bestimmt, die sich im Begriff des Staatskapitalismus ausdriickt, so muß dieser Begriff nun auch als analytischer Ausdruck reflektiert werden; gefragt werden, welche konkreten Erscheinungsformen er bezeichnet. Hier ist eine der Bestimmungen des Staatskapitalismus aufschlußreich, die Lenin in einem Interview selbst gegeben hat, nämlich, daß man in Rußland

„2 eine ganze Reihe von Prinzipien anwendet, die man in der kapitalistischen ökonomik als ¿Staatskapitalismus ${ }^{6}$ bezeichnete.

Zwei Dinge sind hier bemerkenswert. Zum einen, daß Lenin so selbst bestätigt, daß man an eine Begrifflichkeit anknüpfte, die unter den spezifischen historischen Bedingungen der kapitalistischen Kriegswirtschaft entstanden war. Zum anderen aber, daß dieser Begriff kein gesellschaftliches Produktionsverhältnis ausdrückt, sondern bestimmte „Prinzipien" der ,organisatorischen Form der Arbeit" (175). Als ,Prin$z i p$ “ des Staatskapitalisnuus begreift Lenin ,etwas Zentralisiertes, Durchgerechnetes, Kontrolliertes und Vergeselischaftetes" (176), das sich in einem ganzen Spektrum konkreter Erscheinungsformen manifestiert: Syndikate, ,staatskapitalistische“" Monopole, Zwangssyndizierung, Großbanken (177), ,Getreidemonopol, unter Kontrolle stehende Unternehmer und Händler, bürgerliche Genossenschaftler" (178), zentralistische Leitung der Industrie, Arbeitsdisziplin (179), aber auch die Privilegierung bürgerlicher Spezialisten (180). Der Begriff des Staatskapitalismus bleibt bei der Kennzeichnung der konkreten Erscheinungsformen also äußerst vage; diese ste-

172) ders., Wie soll man den Wettbewerb organisieren?, in: A.W II, S. 590

173) ders., Tagung des Gesamtrussischen Zentralexekutivkomitees, a. a. O., S. 285. Diese drei Momente führt Lenin auch in seiner Polemik gegen die ,linken Kommunisten“" an. Vgl. Úber, linke' Kinderei..., a. a. O., S. 786

174) ders., Interview für den Korrespondenten des ,Manchester Guardian', Zweite (unvollendete) Variante, in: LW 33, \$. 394

175) Die Nicht-Kennzeichnung eines gesellschaftlichen Produktionsverhältnisses fiuhrt dann bei Lenin auch dazu, daß er von einem, ,Staatskapitalismus unter der Diktatur des Proletariats " sprechen muß.

176) ders., Tagung des Gesamtrussischen Zentralexekutivkomitees, a. a. O., S. 285

177 ) ders., Staat und Revolution, in: AW II, S. 359, 402; ders., Werden die Bolschewiki ..., a. a. O., S. $461 \mathrm{ff}$.

178) ders., Über, linke $\mathrm{K}^{6}$ indereí..., a. a. O., \$. 787

179) ders., Tagung des Gesamtrussischen Zentralexekutivkomitees, a. a. O., S. 287; Die nächsten A ufgaben der Sowjetmacht, in: AW II, S. 753

180) ders., Tagung des Gesamtrussischen Zentralexekutivkomitees, a. a. O., S. 302. Vgl. auch ders., Die nächsten Aufgaben..., a. a. O., \$. $743 \mathrm{ff}$. und Über ,linke Kinderei.... a. a. O., \$. 799 
hen lediglich als Beispiele für die Durchsetzung einer ,Rechnungsführung und Kon* trolle. ${ }^{6}$

Wenn Lenin 1918 den Staatskapitalismus (neben patriarchalischer Bauernwirtschaft, kleiner Warenproduktion, privatwirtschaftlichem Kapitalismus und Sozialismus) auch als ein "Element ${ }^{66}$, einen "Typus ${ }^{66}$ der ,ökonomischen Gesellschaftsstruktur" (181) Rußlands anführt, so ist das daher sicherlich nicht in dem buchstäblichen Sinne zu interpretieren, daß es einen ,staatskapitalistischen" Sektor gesellschaftlicher Produktion gegeben habe (182); eine der häufigsten Interpretationen (183). Der primär praxisorientierte Sinn des Begriffs Staatskapitalismus verweist lediglich auf die allgemeine Notwendigkeit einer Übergangsperiode zum Sozialismus und das Prinzip dieser sozialistischen Transformation, deren Entwicklungstendenz durch den Grad der Vergesellschaftung der Arbeit als Einheit von Entwicklung der Produktivkräfte und Sowjetdemokratie definiert wird.

Aber als Prinzip der sozialistischen Transformation ist der Begriff des Staatskapitalismus 1918 bei Lenin selbst äußerst zwieschlächtỉg. Denn unter der Voraussetzung einer baldigen deutschen Revolution orientiert sich die Lenin'sche Taktik der sozialistischen Transformation an den Maßnahmen der deutschen Kriegswirtschaft (und damit auch an der durch sie produzierten ideologischen TheorieForm) (184), die im Grunde nur negativ die gesellschaftliche Struktur Rußlands zum Ausdruck bringt: als noch fehlende Vergesellschaftung der Arbeit, die durch die Kombination der beiden ,Hälften" des Sozialismus überwunden werden kann.

Mit dem Übergang zur Neuen Ökonomischen Politik als Ergebnis der internationalen Entwicklung, der durch den Bürgerkrieg zerstörten Produktivkräfte und der während der Periode des ,Kriegskommunismus ${ }^{66}$ entstandenen gesellschaftichen Konflikte, erhält der Begriff des Staatskapitalismus eine veränderte Bedeutung (185).

„Die ungeheuerliche wirtschaftliche Zerrüttung des Landes, der Mangel an Brennmaterial, Rohstoffen und Transportmitteln führt dazu, daß die Kleinproduktion getrennt vom Sozialismus besteht. "(186)

181) ders., Über, linke' Kinderei ..., a. a. O., \$. 787

182) Lenin spricht an derseiben $S$ telle von der, ,Hüle des Staatskapitalismus ${ }^{46}$.

183) Vgl. etwa Szentes, a. a. O., S. 311. Dobb und Bettelheim gehen sogar so weit, von der Zeit bis Sommer 1918 als von einer, „Phase des Staatskapitalismu s ${ }^{66}$ zu sprechen, ganz im Kontext der Etappentheorie. (Charles Bettelheim, L'économie soviétique, Paris 1950 , S. $8 \mathrm{f}$; Maurice Dobb, Soviet Economic Development since 1917, London 1948, S. $82 \mathrm{ff}$.)

184) Eine Ausnahme in der Verwendung des Staatskapitalismus-Begriffs stellt offensichtlich die Brivilegierung der Spezialisten dar: „Der Staatskapitalismus besteht nicht in Geld, sondern in den gesellschaftlichen Verhältnissen. Wenn wir aufgrund des Dekrets ïber die Eisenbahnen Gehälter von 2000 Rubel zahlen, so ist das Staatskapitalismus." Lenin, Tagung des Gesamtrussischen Zentralexekutivkomitees, a.a. O., S. 302) Diese Verwendung ist sowohl von der bei Lenin 1918, wie auch der während der Periode der Neuen Okonomischen Politik üblichen verschieden; obwohl sie ihrem Inhalt nach viel konkreterer Ausdruck der ökonomischen Rückständigkeit Rußlands ist, und damit der Bedeutung des Staatskapitalismus während der NEP nahekommt.

185) Vgl. hierzu auch Autorenkollektiv Projekt Klassenanalyse, a.a. O., S. $660 \mathrm{f}$.

186) Lenin, Referat über die Naturalsteuer in der Versammlung der Sekretäre und verantwort- 
Unter diesen Bedingungen ist der Handel ,die einzig mögliche ökonomische Verbin. dung zwischen den vielen Millionen kleiner Landwirte und der Großindustrie" (187), da der 1918 intendicrte ,Sturmangriff" zur Schaffung einer industriellen Großproduktion nicht realisiert werden konnte. Dieser gescheiterte Aufbau einer Industrie, die die Landwirtschaft mit billigen Produkten versorgen könnte, führt so nicht nur zu veränderten Distributionsverhältnissen, sondern sowohl in der Industrie, als auch der Landwirtschaft teilweise zur, ,Zulassung ${ }^{6}$ von kapitalistischen Verhältnissen, deren ,naturwüchsige ${ }^{6}$ Entfaltung allerdings durch den veränderten gesellschaftlichen Reproduktionsprozeß einerseits begrenzt ist, andererseits mit diesem konfligiert.

Diese ,neue Form des Kapitalismus" kennzeichnet Lenin mit ,Staatskapitalismus" (188), der jetzt allerdings eine andere Bedeutung erhält als 1918.

„Als wir ... im Fruhjahr 1918 die Frage des Staatskapitalismus stellten, da wurde sie nicht so gestellt, daß wir zuruckgehen zum Staatskapitalismus, sondern so, daß unsere Lage leichter und die Lösung unserer sozialistischen Aufgaben näher wäre, wenn wir in Rußland den Staatskapitalismus als herrschendes Wirtschaftssystem hätten." (189)

Dieser ,Rückzug zum Staatskapitalismus“ bedeutet 1921 eine unvermeidliche Entwicklung von Elementen des Kapitalismus, die unter der Bedingung der Diktatur des Proletariats in das ,Fahrwasser des Staatskapitalismus ${ }^{66}$ (190) gelenkt werden sollen. Diese Elemente des Kapitalismus resultieren aus der Freiheit des Handelns, der Freiheit der Genossenschaften, der Verpachtung von industriellen und landwirtschaftlichen Klein. und Mittelbetrieben an inländische kapitalistische Unternehmer und den Konzessionsverträgen mit ausländischen kapitalistischen Unternehmen.

Aber diese Elemente des Kapitalismus sind in ihrer Entwicklung beschränkt, allein schon durch die Tatsache, daß private Kapitalproduktion nur im Bereich der Klein und Mittelbetriebe möglich ist.

${ }_{2}$ Dieser Kapitalismus wird unter Kontrolle, unter Aufsicht des Staates stehen. Hat der Arbeiterstaat von den Fabriken, Werken und Eisenbahnen Besitz ergriffen, so schreckt uns dieser Kapitalismus nicht." (191)

Die „Freiheit ${ }^{65}$ der Genossenschaften (192) ist auf deren Überschüsse begrenzt, private Händler arbeiten auf Provisionsbasis als Kommissionäre staatlicher

lichen Vertreter der Zellen der ${ }^{2} P R$ (B) der Stadt und des Gouvernements Moskau, in: LW 32, S. 306

187) ders., Über die Bedeutung des Goldes jetzt und nach dem vollen Sieg des Sozialismus, in: AW III, S.741

188) ders., III. Kongreß der Kommunistischen Internationale, Referat über die Taktik der KPR, in: LW 32, S. 514

189) ders., VIl. Moskauer Gouvernements-Parteikonferenz, Referat über die Neue Ökonomische Politik, in: LW 33, S. 69

190) ders., Über die Naturalsteuer, in: AW III, S. 684

191) ders., Referat über die Naturalsteuer, a. a. O., S. 307

192) Den genossenschaftlichen Kapitalismus bezeichnet Lenin als ein dem Staatskapitalismus „ähnlichen" ${ }^{\prime K}$ apitalismus. Vgl. Lenin, Uber die Naturalsteuer, a.a. O., S. 685. Später modifiziert Lenin diese Position, wenn er schreibt, $d a ß$, , sich die Genossenschaften unter 
Handelsorganisationen, Verpachtung und Konzessionen an private Kapitalisten erfolgen auf Vertragsbasis (193), bzw. ist private Kapitalproduktion nur in Form sog. ,gemischter Gesellschaften" möglich (194) - das sind die Einschränkungen der Entwicklung privaten Kapitals, die konkreten Vermittlungsformen der ,Aufsicht des Staates“.

„Der Staatskapitalismus, den wir bei uns geschaffen haben, ist ein eigenartiger Staatskapitalismus. Er entspricht nicht dem gewöhnlichen Begriff des Staatskapitalismus. Wir halten alle Kommandohöhen in unseren Händen, wir haben den Grund und Boden, der dem Staat gehört." (195)

„,... Entwicklung des Kapitalismus unter Kontrolle und bei Regulierung durch den proletarischen Staat (d. h。 in diesem Sinne des Wortes, ,Staats"kapitalismus) . . " (196)

In all diesen Bestimmungen des Staatskapitalismus wird deutlich, daß dieser Begriff die spezifische Beziehung von privatem Kapital und proletarischem Staat zum Ausdruck bringt, und insofern tatsächlich ein "eigenartiger Staatskapitalismus ${ }^{66}$ ist. Er kennzeichnet weder ein sozio-ökonomisches System, noch einen Sektor gesellschaftlicher Produktion, noch ein gesellschaftliches Produktionsverhältnis überhaupt. Preobrazenskij hat daher auch den Staatskapitalismus (im Lenin'schen Gebrauch) als eine Kennzeichnung der „Zwischenverhältnisse“ interpretiert, als den „verbindenden Stoff $f^{\text {" }}$ der beiden grundlegenden Produktionsverhältnisse, der "sozialistischen Form" der Produktion und der Warenproduktion (197). Diese treffende Kennzeichnung des Staatskapitalismus enthüllt aber zugleich, daß dieser Begriff als analytische Kategorie ungenügend ist; eine Kategorie, bei deren Verwendung auch noch 1922 betont werden muß, ,daß der Staatskapitalismus bei uns, jetzt nicht dasselbe ist, worüber die Deutschen geschrieben haben." (198)

Die eigentliche Bedeutung dieses Begriffs liegt aber auch hier in seiner Kennzeichnung einer bestimmten Praxisform. Denn er reflektiert jetzt als Praxisform - nach der Isolierung der russischen Revolution und den Erfahrungen des „Kriegskommunismus" - die konkreten Bedingungen der sozialistischen Transformation im ökonomisch rückständigen Land, die Notwendigkeit des teilweisen Fortbeste-

unseren Verhältnissen in der Regel völlig mit dem Sozialismus (decken). "Lenin, Über das Genossenschaftswesen, in: A W III, $\$ .864$

193) ders., Über die Naturalsteuer, a. a. O., S. $683 \mathrm{ff}$.

194) ders., XI. Parteitag der KPR (B), Politischer Bericht des Zentralkomitees der KPR (B), in: AW III, S. $776 \mathrm{f}$.

195) ders., IV. Kongreß der kommunistischen Internationale, Fünf Jahre russische Revolution und die Perspektiven der Weltrevolution, in: AW III, S. 822

196) ders., Thesen zum Referat auf dem III. Kongreß der Kommunistischen Internationale über die Taktik der KPR (ursprünglicher Entwurf), in: AW III, S. 711. Im Anschluß an Lenins Referat übernimmt nun auch Bucharin diesen Begriff des, ,Staatskapitalismus": „Die Eigentumsverhältnisse und die entsprechenden Produktionsverhältnisse sind ganz anders. Das ist eine eigenartige ökonomische Struktur, die man, theore tisch gesprochen, nicht mit dem üblichen ,Staatskapitalismus" in dem gewöhnlichen Sinne des Wortes verwechseln kann。" (Protokoll des III. Kongresses der Kommunistischen Internationale, Hamburg 1921, Reprint, S. $802 \mathrm{f}$.

197) Preobrazenskij, Neue O̊konomik, a. a. O., S. 370

198) Lenin, XI. Parteitag der KPR (B), Schlußwort zum politischen Bericht des ZK der KPR (B), in: LW 33, S. 298 
hens bürgerlicher Verhältnisse zur Entwicklung der Produktivkräfte bei gleichzeitigem Kampf um ihre Zuruickdrängung (199): eine „Fortsetzung des Klassenkampfes in anderer Form, keinesfalls aber eine Ersetzung des Klassenkampfes durch Klassenfrieden." (200) (Auf die Konsequenzen, die sich hieraus etwa für die Bïndnispolitik, die Rolle der Gewerkschaften und den Kampf gegen den ,Bürokratismus" ergeben, kann hier nicht mehr eingegangen werden). (201)

Dieser "Staatskapitalismus" verweist also nicht mehr auf Analogien zu Maßnahmen des bürgerlichen Staates (im Sinne einer noch fehlenden Vergesellschaftung der Arbeit im ökonomisch rückständigen Rußland), sondern geht von den auf Basis dieser Rückständigkeit partiell fortbestehenden bürgerlichen Verhältnissen im eigenen Land aus und formuliert den Weg ihrer Zurückdrängung. Das scheint mir der entscheidende Unterschied der Lenin'schen Verwendung des Staatskapitalismus-Begriffs während der NEP gegenüber 1918 zu sein, die so die Entwicklung seit 1918 und die daraus resultierenden veränderten Bedingungen der sozialistischen Transformation aufnimmt.

In einer seiner letzten Arbeiten ging Lenin im Januar 1923 nochmals auf die Frage des ,Staatskapitalismus ${ }^{66}$ ein, da die Verwendung dieses Begriffs, ,des öfteren Zweifel bei manchen jungen Genossen" erregt hatte, die ,worwiegend die abstrakt politische Seite " betrafen. In diesem Zusammenhang führt Lenin aus:

„Sie merkten jedoch nicht, daß die Bezeichnung ,Staatskapitalismus" ${ }^{46}$ bei mir gebraucht wurde: Erstens um den historischen Zusammenhang unserer gegenwärtigen Position mit der Position in meiner Polemik gegen die sogenannten linken Kommunisten herzustellen, ... mir lag daran, don kontinuierlichen Zusarnmenhang des gewöhnlichen Staatskapitalismus mit jenem ungewöhnlichen, sogar ganz und gar ungewöhnlichen Staatskapitalismus festzustellen, von dem ich sprach, als ich den Leser in die Neue Ökonomische Politik einführte.

Zweitens war für mich stets der praktische Zweck wichtig." (202)

Die agitatorische und praxisorientierte Bedeutung des Begriffs Staatskapitalismus war für Lenin allein ausschlaggebend: der, historische Zusammenhang ${ }^{66}$ 1918-1921 steht für die Notwendigkeit (wenn auch bei äußerst unterschiedlichen Formen) eines „Rückzuges“ gegenüber der Illusion, im ökonomisch rückständigen Land unmittelbar zum Sozialismus überzugehen - der ,praktische $\mathbb{Z}$ weck" schließlich orientiert sich daran, wie unter den jeweils gegebenen Bedingungen die Transformation zum Sozialismus möglich ist.

In diesem Sinne war der „Staatskapitalismus" keineswegs ,eine spezifische Erscheinungsform der Diktatur des Proletariats in Sowjetrußland" (203), sondern

199) Vgl. etwa Lenin, Die Neue Ökonomische Politik und die Aufgaben der Ausschüsse für politisch-kulturelle Aufklärung, in: LW 33, S. 45 f.; ders, XI. Parteitag der KPR (B), a. a. O., S. $776 \mathrm{ff}$; ders., Plan der Rede fur den 27. 3.1922, in: LW 36, S. $556 \mathrm{f}$.

200) ders., Uber die Naturalsteuer, a. a. O., S. 684

201) Zum Zusammenhang von „Staatskapitalismus" und Bündnispolitik vgl. etwa Lenin: Neue Zeiten, alte Fehler in neuer Gestalt, in: LW 33, S. 5 ff. Zur Gewerkschaftsfrage: ders., Über die Rolle und die A ufgaben der Gewerkschaften unter den Verhälnissen der Neuen Ökonomischen Politik, in: AW III, S. $744 \mathrm{ff}$. Zum, Bürokratismus": ders., Über die Naturalsteuer, a. a. O., S. 689 ff.; ders., Brief an M. Sokolow, in: LW 35, S. $467 \mathrm{f}$.

202) ders., Über das Genossenschaftswesen, a. a. O., S. 863

203) Rabehl, Die marxistische Theorie der Transformationsgesellschaft ..., a. a. O., S. 261 
vielmehr ein historisch bedingter, ideologischer Begriff zur Kennzeichnung bestimmter Praxisformen des Übergangs zum Sozialismus (204), der daher - obwohl als ideologischer Begriff - durchaus Widersprüche dieser Transformation offenlegen konnte. In diesem allgemeinen, praktischen Sinne, nicht jedoch als theoretischer Begriff (evtl. mit dem Anspruch der Kennzeichnung von spezifischen Produktionsverhältnissen) ist der Begriff des, ,Staatskapitalismus ${ }^{68}$ bis heute von Bedeutung geblieben. Es wird jetzt im folgenden zu zeigen sein, was demgegenüber eine Theorie des Staatskapitalismus impliziert, die beansprucht, mit dieser Begrifflichkeit die gesellschaftliche Wirklichkeit der Übergangsgesellschaften zu reproduzieren; wobei ich mich darauf beschränken muß, die methodischen Implikationen, die jeweilige Konzeption von Geschichte zu zeigen.

\subsection{Zur Existenz eines Staatskapitalismus in den Übergangsgesellschaften}

\subsubsection{Die sozialdemokratische Variante (Otto Bauer)}

Wenn im folgenden das Begründungsmuster der sozialdemokratischen Variante skizziert wird, so sind dazu zunächst einige allgemeine Bemerkungen notwendig.

1. Die sozialdemokratische Kritik der russischen Revolution läßt sich nicht auf eine Theorie des Staatskapitalismus reduzieren. Das Spektrum der Termini, die zur Kennzeichnung der russischen Entwicklung gebraucht wurden, reichte von der „,asiatischen Despotie“, der ,Staatssklaverei" bis zur Gleichsetzung mit Zarismus, Imperialismus und Faschismus (205).

2. Aber auch da, wo die Entwicklung der Sowjetunion als die eines Staatskapitalismus gekennzeichnet wurde, ist es niemals zu einer Ausarbeitung einer homogenen Theorie des Staatskapitalismus gekommen. Der Grund dafür scheint mir darin zu liegen, daß die eigene Taktik der Sozialdemokratie (mit der ihr zugrundeliegenden Staatstheorie, ihrer „Keimzellen"-Theorie der Sozialisierung etc.) selbst unter Verdacht stand, lediglich zu einem „Staatskapitalismus $^{66}$ zu führen. Das Lieblingsthema der Sozialdemokratie war daher auch das

204) Erscheinungsformen dessen, was Lenin unter dem Begriff des „Staatskapitalismus" faßte, existierten auch etwa in Cuba und in der VR China. Man vgl. allerdings, wie etwa Che Guevara diese Erscheinungsformen und einen diesbezüglichen Text von Lenin diskutiert - ohne allerdings von "Staatskapitalismus" zu sprechen. (Ernesto Che Guevara, Über das Budget-Finanzierungssystem, in: Bettelheim, Castro, Guevara, Mandel, Mora, Wertgesetz, Planung und Bewußtsein. Die Planungsdebatte in Cuba, Frankfurt 1969, S. $47 \mathrm{ff}$.) Oder Texte von Mao, in denen er den Zusammenhang von „,neuer Demokratie ${ }^{\text {“6 }}$ und fortbestehenden, kapitalistischen Verhältnissen thematisiert. (Mao Tse-tung, Über die Koalitionsregierung, in: Ausgewählte Werke Band III, Peking 1969, insb. S. $267 \mathrm{ff}$. und ders., Die gegenwärtige Lage und unsere Aufgaben, in: A usgewählte Werke Band IV, insb. S. $172 \mathrm{ff}$.)

205) Über die Einschätzung der Entwicklung der russischen Revolution durch die deutsche Sozialdemokratie informiert Peter Lösche, Der Bolschewismus im Urteil der deutschen Sozialdemokratie 1903-1920, Berlin 1967; über die der österreichischen Sozialdemokratie Norbert Leser, Die Odyssee des Marxismus. Auf dem Weg zum Sozialismus, Wien 1971 , insb. S. 75 ff. 
Verhältnis von Demokratie und Diktatur des Prole tariats.

3. Die Kritik der russischen Revolution war in dem Maße irrational und emotional, wie die sozialdemokratischen Parteien sich einer starken kommunistischen Partei im eigenen Land gegenübersahen. Das ist ein wesentlicher Erklärungsfaktor dafür, daß die Kritik der österreichischen Sozialdemokratie (da in Österreich nur eine schwache KP existierte) nicht jene Exzesse und Grotesken (206) hervorbrachte, die Teile der deutschen Sozialdemokratie kennzeichnen (207). Das rechtfertigt es auch, daß im folgenden die sozialdemokratische Variante einer Theorie des Staatskapitalismus gerade am Beispiel eines Vertreters der österreichischen Sozialdemokratie, Otto Bauer, entwickelt wird.

Eine Besonderheit der sozialdemokratischen - auch der Bauerschen - Kritik der Sowjetunion besteht zweifellos darin, daß die Kriterien dieser Kritik aus der Zeit vor der Oktoberrevolution stammen; diese Kriterien daher nicht unmittelbare Widerspiegelung des realen Transformationsprozesses sind, sondem Kriterien, die von dessen Unmöglichkeit ausgehen: der „Unreife“ der objektiven Bedingungen für den Aufbau des Sozialismus im ökonomisch rückständigen Rußland. Die reale Entwicklung fungiert daher weitgehend als nachträgliche Bestätigung vorformulierter Thesen.

Auch Otto Bauer prognostiziert vor der Oktoberrevolution, daß die russische Revolution nur eine bürgerliche Revolution sein könne.

„Rußłland ist ein Agrarland, in dem die Arbeiter eine Minderheit der Bevölkerung sind. Die russische Revolution kann nicht mit der Diktatur des Proletariats enden, sie kann nicht eine sozialistische Gesellschaftsordnung aufrichten ... Siegt also die russische Revolution, so wird ihr Ergebnis eine bürgerliche Republik sein." (208)

Als aber die russische Revolution doch mit der Diktatur des Proletariats endete, schreibt Otto Bauer 1920:

"Die Diktatur des Proletariats in Rußland ist nicht die Überwindung der Demokratie, sondern eine Phase der Entwicklung zur Demokratie. Der Despotismus des Proletariats hat die geschichtliche Aufgabe die bäuerliche Masse des russischen Volkes aus der Kulturlosigkeit, in der sie der zarische Despotismus erhalten hat, emporzuheben und dadurch erst die Voraussetzungen der Demokratie in Rußland zu schaffen. Die Dikitur des Proletariats in Rußland ist ... nur eine Durchgangsphase der russischen Entwicklung ..." (209)

206) Eine dieser Grotesken sei hier zitiert. Karl Kautsky mißt die russische Entwicklung an der Pariser Commune und schreibt: „Deren Diktatur des Proletariats hat sich nie auf Bauernräte gestützt.“ (Terrorismus und Kommunismus, Berlin 1919, zitiert nach der 2. Auflage von 1925, S. 109)

207) Darauf machen Leser, a. a. O., S. 194 und Lösche, a. a. O., \$. 260, aufmerksam. Lösche arbeitet zudem heraus, zu welchen Zeitpunkten etwa die deutsche Sozialdemokratie ihre Kritik vorübergehend zurückstellte (etwa während des $\mathbb{I}$. Weltkrieges und nach dem März 1917), zu Zeitpunkten, wo die russische Revolution für die Taktik der deutschen Sozialdemokratie funktionalisierbar war.

208) Heinrich Weber (Pseudonym für Otto Bauer), Die russische Revolution und das europäische Proletariat, Wien 1918, S. 26 f.

209) Otto Bauer, Bolschewismus oder Sozialdemokratie?, Wien 1920, S. 69 
Bauer leugnet nicht den proletarischen Charakter der russischen Revolution, bestätigt, daß sie als soziale Revolution die bestehenden kapitalistischen Verhältnisse transformiere. Aber zugleich subsumiert er diese reale Entwicklung unter die vorformulierten Schemata, die von ihrer Unmöglichkeit ausgehen.

„Es ist eine sozialistische Gesellschaft, die da entsteht. Denn die Sowjetmacht hat die Arbeitsmittel den Kapitalisten entwunden, den Arbeitsprozeß von der Herrschaft des Kapitals befreit, die Verfügung über den Arbeitsertrag den Kapitalisten entrissen und sie selbst organisiert jetzt... eine planmäßige, unmittelbar gesellschaftliche Verteilung des Arbeitsertrages. Aber wenn das Sozialismus ist, so ist es doch ein Sozialismus besonderer Art, ein despotischer Sozialismus." (210)

Dieser ,despotische Sozialismus“ sei das ,notwendige Produkt ... der russischen Kulturlosigkeit", aber zugleich ,eine ,transitorische Notwendigkeit", ein zeitweilig unentbehrliches Instrument des historischen Fortschritts" (211). Mit dieser doppelten Notwendigkeit, die den ,historischen Fortschritt" exekutiert, wird sowohl die Realität der Diktatur des Proletariats als auch deren nur vorübergehende Existenz begründet; damit die Realität jenen Schemata angepaßt, hinter denen die „,bürgerlich-demokratische Republik" lauert (212).

Mit dem Übergang zur Neuen O̊konomischen Politik scheint sich die russische Revolution tatsächlich den Schemata zu unterwerfen, die mit der, Marxschen Geschichtsauffassung "identifiziert werden (213).

„Es ist eine kapitalistische Wirtschaft, die wir so wiedererstehen sehen: eine kapitalistische Wirtschaft, die von der neuen Bourgeoisie beherrscht wird ..." (214)

Da diese „Restauration des Kapitalismus" aber nur der Abklatsch vorab formulierter Schemata ist, muß der Nachweis ihrer Existenz schwierig werden. Er ist nicht nur dadurch gekennzeichnet, daß der verstaatlichte Sektor völlig ,übersehen“ wird,

210) ebd., S. 62 f. Bauer spricht an anderer Stelle auch von einem, Staatssozialismus in seiner schärfst ausgeprägten, brutalsten Form" (ebd., S. 98).

211) ebd., S. $63 \mathrm{f}$.

212) ebd., S. 70 f. Der Interpretation, Bauer habe seine Einschätzung der russischen Revolution 1920 revidiert, weil er von ,despotischem Sozialismus" gesprochen habe, kann nicht zugestimmt werden (so Leser, a. a. O., S. 93). Bauer bestätigt gerade 1921 die Kontinuität seiner Einschätzung. Vgl. Anm. 213. Aufschlußreicher ist hier schon der Briefwechsel zwischen Bauer und Kautsky 1920, in dem Bauer begründet, daß seine Schrift ,durch den Wunsch bestimmt (sei), die Einheit der österreichischen Arbeiterklasse zu bewahren. " (Melvin Croan, Perspektiven der sowjetischen Diktatur - Otto Bauer, in: Der Revisionismus, hrsg. von Leopold Labedz, Köln 1965, S. 478 f.) Das erklärt die Funktion der "doppelten Notwendigkeit“. Für die Periode des Übergangs vom „despotischen " zum „,demokratischen“" Sozialismus respektiert Bauer die Möglichkeit von ,gesellschaftlichen Mischformen ... , die unsere aus den Erfahrungen der Vergangeheit abstrahierte Wissenschaft noch nicht zu klassifizieren vermag." (Bauer, Bolschewismus ..., a. a. O., \$. 70)

213) ,Der ,neue Kurs" ... hat meine Prognosen bestätigt. . . Die Geschichtsauffassung, die Marx uns gelehrt hat, wäre uns nichts nütze, wenn sie uns nicht befähigte, den gewaltigsten Klassenkampf unserer Zeit anders, tiefer $z u$ begreifen als aus den durch die Leidenschaft des Kampfes genährten Ideologien, Illusionen der Kämpfenden selbst." (Bauer, Der ,neue Kurs in Sowjetrußland, Wien 1921, S. 4 und S. 6)

214) ebd., S. 20 
auch sonst ersetzt die „Logik“ und die „Notwendigkeit " die Explikation durch Tatsachen.

Die NEP sei die ,Kapitulation der Sowjetregierung vor der Bauernschaft", mit der eine „Restauration des Handelskapitals“" (215) und die Entstehung einer , ,neuen Bourgeoisie" (216) einhergehe. Und von dieser Feststellung aus, vollzieht sich dann die ,Restauration des Kapitalismus“ ${ }^{*}$ von selbst:

,Sobald der Widerstand der Bauernmasse der Sowjetregierung die Rückkehr zum freien Handel aufzwang, wurde durch die innere Logik des Handels selbst die ganze kapitalistische Wirtschaftsordnung wiederhergestellt", worin ,der Grundgedanke der Marxschen Geschichtsauffassung seine Bestätigung (findet)." (217)

„Der russische Kommunismus war ... nur das Mirtel der Geschichte ... die Voraussetzungen der Entwicklung des Kapitalismus auf neuer, verbreiteter Grundlage zu schaffen." (218)

In der Bauerschen Theorie ersetzt die ,Logik der objektiven Verhältnisse ${ }^{66}$ die Reproduktion des Konkreten; was bedeutet, daß sich Geschichte außerhalb der Praxis agierender Subjekte konstituiert, sich quasi von selbst volizieht und dabei der „ökonomischen Notwendigkeit" (219) gehorcht.

Haben sich so schon einmal die Schemata der Unmöglichkeit des Aufbaus des Sozialismus im ökonomisch rückständigen Land „,bewährt“, so wird mit ihnen nun auch die weitere Entwicklung prognostiziert - denn die Diktatur des Proletariats widerspricht ja noch der ,Restauration des Kapitalismus" (bzw. den Schemata).

„Die reale Praxis des ,neuen Kurses" ist der Wiederaufbau einer kapitalistischen Wirtschaft. Aber den Wiederaufbau des Kapitalismus glaubt er (Lenin - d. Verf.) vollziehen zu können unter der ,Diktatur des Proletariats". Das ist immer noch lllusion, immer noch Utopie ... Ihre Liquidation ist unvermeidlich ..." ", worin sich ,abermals Marxens Lehre (bestätigt), daß der Umwälzung der ökonomischen Basis die Umwälzung des ganzen politischen und juristischen Überbaues folgen muß." (220)

215) ebd., S. 15

216) ebd., S. 16. Unter ,neue Bourgeoisie" rechnet Bauer sowohl Schleichhändler und Kriegsgewinnler als auch die ,Sowjetbürokratic ... der sozialisierten Unternehmungen“, wobei bei letzteren die Tatsache der Korruption sie als „Klasse" konstituiert. Ja, Bauer schreibt sogar, daß diese "neue Bourgeoisie "im Handel "eine legale Verwertung ihres Kapitals" (S. 17) gefunden habe. Seltsames „,Kapital", das sich im Handel ,verwertet".

217) ebd., S. 20. Wenn an manchen Stellen statt von ,innerer Logik" von Tatsachen die Rede ist, muß Bauer allerdings zugestehen, daß nur ,wenige große Betriebe ... tatsächlich verpachtet (wurden) ${ }^{\text {c }}$, ,nur wenige und unbeträchtliche Konzessionen erteilt werden (konnten)" (S. 23 f.) etc.

218) ebd., S. 31

219) ebd., S. 36. Sieh dabei auf Marx zu berufen, heißt „vergessen", daß Marx von einer historischen $\mathrm{G}$ esełzmäßigkeit ausging, die immer die Praxis von Menschen bzw. Klassen mit einschloß, die "ökonomischen Verhältnisse" daher nie eine determinierte Notwendigkeit, sondern nur eine reale Möglichkeit begründeten. Vgl. Helmut Fleischer, Die Idee der historischen Notwendigkeit im historischen Materialismus, in: Sozialphilosophische Studien, Westberlin 1973, insb. S. 21 ff.

220) ebd., S. 33 f. und S. 27. Die Liquidation der Diktatur des Proletariats könne dabei entweder auf dem Wege der „,blutigen Konterrevolution“ erfolgen, oder aber ,allmählich, friedlich abgebaut" werden, wobei auf letzterem Wege ,keimkräftige Elemente einer sozialistischen Weiterentwicklung" (S. 35) erhalten blieben; vielleicht so ,keimkräftig" wie die Arbeit der österreichischen Sozialisierungskommission, von der bis 1925 nur die 
Der Sinn dieser prognostizierten Umwälzung des Überbaus, der Liquidation der Diktatur des Proletariats, liegt denn auch darin, jene "Rechtssicherheit" zu schaffen, die in- und ausländische Kapitalisten zur "Kapitalanlage ${ }^{\text {" }}$ in Rußland anregen soll (221); mithin soll durch sie erst die Voraussetzung dafür geschaffen werden, was Bauer bereits ,bewiesen" hatie: die "Restauration des Kapitalismus".

Werden in der Bauerschen Theorie die ,objektiven Verhältnisse " zu den Subjekven der Geschichte hypostasiert, so muß diese Theorie gerade an ihrer eigenen Voraussetzung scheitern: an der Veränderung der ,objektiven Verhältnisse" (sofem diese selbst noch auf die statistische Erfassung der ökonomischen Rückständigkeit reduziert werden). In der Entwicklung der Bauerschen Kritik der Sowjetunion hat sich gerade dieser Prozeß vollzogen.

Unter dem Eindruck von Weltwirtschaftskrise und Faschismus sinerseits, der wirtschaftichen Erfolge des 1. Fünf.Jahres-Planes in der Sowjetunion andererseit:, revidiert Bauer seit 1931 die These eines Zusammenbruchs der Sowjetunion. Ir schreibt:

"N) Nur wer nicht fähig ist, aus neuen Tatsachen, aus Tatsachen weltgeschichtlicher Bedeutung $z u$ lernen, kann heute noch an Fehlurteilen festhalten, die in den Jahren 1917-21 begreiflich und verständlich waren." ${ }^{\text {(22) }}$

Dieses „Lemen“ Otto Bauers zeigt sich insbesondere darin, daß er jetzt zugest ht, daß sich in der Sowjetunion ein ,sozialistischer Unabau der Gesellschaft" vollzizhe, die Sowjetunion ,einen großen Teil des Umwandlungsprozesses von der kapitalistischen zur sozialistischen Gesellschaft schon zurückgelegt" (223) habe, wenn auch - unter der Bedingung der "terroristischen Diktatur" - bei ,ungeheuerlicher Unwirtschaftlichkeit“ (224). Die Perspektive:

„In dem Maße, als die Lebenshaltung der Volksmassen wird gebessert werden können, wird die terroristische Diktatur überflüssig und abgebaut, das Sowjetregime demokratisiert werden können. Wenn die Diktatur, die über den staatlichen Produktionsapparat verfügt, von einer Demokratie der werktätigen Massen abgelöst wird, wird aus dem Staatskapiralismus der Diktatur eine sozialistische Organisation der Gesellschaft." (225)

Werden so zwar einige inhaltliche Aussagen frïherer Kritiken zurückgenommen (226), so bleibt aber selbst noch in dieser Modifikation das frühere Begrün-

Arsenal-Werke ubrigblieben - „Keime", die nicht so recht "keimen" wollen.

221) ebd., S. $25 \mathrm{ff}$.

222) Otto Baver, Zwischen zwei Weltkriegen? Die Krise der Weltwirtschaft, der Demokratie und des Sozialismus, Bratislava 1936, S. 286

223) ebd., S. 161

224) Otto Bauer, Kapitalismus und Sozialismus nach dem Weltkrieg, Band I: Rationalisierung - Fehlrationalisierung, Wien 1931, S. 219

225) ebd., \$. 220

226) Diese Zurücknahme früherer Positionen - begleitet von dem Wunsch eines, ,integralen Sozialismus", konkret: einer Vereinigung von sozialistischer Arbeiterinternationale und Kommunistischer Internationale - hat innerhalb der internationalen Sozia demokratie erbitterte Kritiker hervorgerufen. Vgl. für viele andere Karl Kautsky, Die Aussichten des Sozialismus in Sowjetrußland, in: Die Gesellschaft, Berlin 1931, 2. Band, S. $420 \mathrm{ff}$. und die Antwort von Otto Bauer, Die Zukunft der russischen Sozialdemokritie, in: Der Kampf, Wien 1931, S. $513 \mathrm{ff}$. 
dungsmuster voll erhalten: die Auffassung von Geschichte als dem Prozeß „ökonomischer Notwendigkeiten ". Im Rückblick erscheint der Verlauf der sozialistischen Transformation seit 1917 als eine, an sich unvermeidliche Entwicklung " (227); ein „,an sich", das Geschichte nicht als Praxis handelnder Subjekte unter gegebenen konkreten Bedingungen kernt.

\subsubsection{Die anarcho-syndikalistische Variante (Helmut Wagner, Otto Rühle)}

Auch bei diesem zweiten Typus der Theorie des Staatskapitalismus ließe sich zeigen, wie Genesis und jeweilige Modifikation dieser $\mathbb{K}$ ritik mit den Praxisformen der Kritiker vermittelt sind. In der deutschen anarcho-syndikalistischen Bewegung entwickelt sich die ursprünglich positive Bewertung der russischen Revolution unter dem Eindruck der Konflikte auf dem II. und III. Weltkongreß der Kommunistischen Internationale 1920/21 und der Lenin-Gorter-Debatte zur Negation der sowjetischen Entwicklung als Staatskapitalismus (228). Von daher steht auch die Parteikonzeption der Bolschewiki im Zentrum ihrer Kritik. Jede Kritik des Transformationsprozesses in der Sowjetunion präsentiert sich als Kritik am Bolschewismus (229), was schon darauf hinweist, daß eher die Theorie dieser Transformation und nicht so sehr deren Realität im Blickpunkt der Kritik(er) steht. Das soll an Texten von Helmut Wagner und Otto Rühle gezeigt werden (230), wobei ich mich auch hier auf die Methode des Nachweises der Existenz eines Staatskapitalismus beschränke.

Helmut Wagner verfaßte 68 ,Thesen über den Bolschewismus“ (231), die dieses Verhältnis von Kritik der Theorie der sozialistischen Transformation und deren Realität sehr plastisch widerspiegeln: nur zwei dieser „Thesen“ beschäftigen sich mit dem Staatskapitalismus.

„Die bolschewistische (!) Wirtschaft ist Staatsproduktion mit kapitalistischen Methoden“",

227) „Unvermeidlich" war ,der schnelle Industrialisierungsprozeß . . auf Kosten des Konsums der Volksmassen" (Bauer, Zwischen zwei Weltkriegen, a. a.O., S. 154), ,,unvermeidlich" auch die Herausbildung eines, allmächtigen, bürokratisch-militärisch-polizeilichen Militärapparats" (S. 156) etc.; „unvermeidlich" dann sicher auch der ,Sozialismus in einem Land" ${ }^{\circ,}$ der , sehr wohl möglich (ist) in einem gewaltigen Lande wie Rußland ..." (S. 201)

228) Vgl, hierzu etwa Olaf Ihlau, Die Roten Kämpfer, Meisenheim am Glan 1969 (2. Abschnitt: Die Stellung der KAPD zur UdSSR und KI), S. 6 ff.

229) Das gilt natürlich nicht ausschließlich für die anarcho-syndikalistische Kritik, obwohl diese wesentlich darauf basiert. Auch Sozialdemokraten haben mit der Diktatur des Proletariats den Bolschewismus kritisiert. Mänchen-Helfen, Rußland und der Sozialismus. Von der Arbeitermacht zum Staatskapitalismus, Berlin 1932, S. 16, spricht sogar von „bolschewistischer Gesellschaft".

230) Wagner und Rühle gehörten Gruppierungen an (der Gruppe ,Rote Kämpfer ${ }^{66}$ bzW. der AAUE), die aus Fraktionierungen der KAPD entstanden. Vgl. Ihlau, a. a. O., S. 179, S. 183

231) Thesen über den Bolschewismus, Westberlin o.J. Zur Authentizität der Autorenschaft Wagners vgl. Ihlau, a. a. O., S. 95 ff. 
wobei unter Methoden die Leitung der Industrie ,nach den Gesichtspunkten kapitalistischer Rentabilität", ,kapitalistisches Entlohnungs- und Antreibersystem" und die „Raffinessen kapitalistischer Rationalisierung "(232) verstanden werden. Aber selbst die dreimalige Voranstellung des Adjektivs, kapitalistisch" begründet noch nicht, daß es sich dabei um kapitalistische Produktion handelt. Sie wird auch im nächsten Satz schlechthin postuliert:

„,Diese Staatsproduktion produziert Mehrwert ... " (233)

Alle weiteren Feststellungen, wie etwa, daß die ,russische Staatswirtschaft ...darum Profitproduktion und Ausbeutungswirtschaft ${ }^{66}$, "Staatskapitalismus unter den historisch einzigartigen Bedingungen des bolschewistischen Regimes" (234) sei, sind tautologische Umformulierungen dieser $\mathbb{P}_{\text {rämisse. }}$

Der eigentliche Schlüssel für den Nachweis der Existenz eines Staatskapitalismus aber liegt in der folgenden These:

„Lenin selbst hatte jedoch von der Sozialisierung der Produktion keine grundlegend andere Vorstellung als die einer bürokratisch geleiteten Staatswirtschaft. Vorbild für sozialistische Organisierung der Produktion waren ihm z. B. die deutsche Kriegsplanwirtschaft oder die Reichs" post ... Ebenso stützte sich Lenin und mit ihm der Bolschewismus überhaupt auf die Sozialisierungsvorstellungen des zentristischen Hilferding ... Der Sozialisierungsbegriff der Bolschewiki ist darum nichts als der Begriff einer vom Staat übernommenen und von seiner Bürokratie von außen und von oben geleiteten kapitalistischen Wirtschaft. Der bolschewistische Sozialismus ist staatlich organisierter Kapitalismus." (235)

Diese These bestätigt, daß sich in der anarcho-syndikalistischen Variante einer Theorie des Staatskapitalismus Geschichte wesentlich aus den Theorie-Formen und Ideologien der agierenden Subjekte konstituiert, die lediglich mit den ,objektiven Verhältnissen", nicht aber mit realen Praxisformen vermittelt werden. Auch hier steht im Hintergrund die apodiktische Aussage:

„Die russische Revolution konnte - ihren historischen Bedingungen nach - von Anfang an nur eine bïrgerliche Revolution sein ... Dem phaseologischen Schema der Entwicklung nach, wie es Marx formuhiert und vertreten hat, hatte in Rußland auf den feudalistischen Zarismus der kapitalistische Bourgeoisstaat $z u$ folgen... Den Kapitalismus aufzurichten und den bürgerlichen Staat zu organisieren ist der historische Beruf der bürgerlichen Revolution. Die russische Revolution war und ist eine bürgerliche Revolution, nicht mehr und nicht weniger: der starke sozialis tische Einschlag ändert nichts an diesem Wesentlichen." (236)

232) These $58 \ldots$, a. a. O., S. 40

233) These $59 \ldots$, ebd.

234) ebd.

235) These 49 .., ebd., S. 32 f. Zum gleichen Interpretationsmuster vgl. Mattick, a. a. O., S. 305; vgl. auch: Die soziale Revolution ist keine Parteisache Nr. 2, Westberlin 1971, \$. 91. Mit dieser Interpretation geht in der Regel auch die Behauptung einher, Le nin selbst habe die russische Staatswirtschaft als Staatskapitalismus bezeichnet. Vgl. etwa: These 48 ... , a. a. O., S. 32; Paul Mattick, Einige Bemerkungen zu Mandels ,Marxistischer Wirtschaftstheorie", in: Die soziale Revolution ..., a. a. O., Nr. 1, S. 108

236) Otto Rühle, Von der bürgerlichen zur proletarischen Revolution (1924), Westberlin 1970, S. 17, S. 21 
Aber weder die aus dem, phaseologischen Schema von Marx" (237) gefolgerte und zum Meta-Subjekt konstituierte "historische Aufgabe" noch die Theorie.Formen der Akteure sind identisch mit der geschichtlichen Praxis selbst. Ohne deren Explikation ist der Saiz

"Lenins ,Orthodoxie' war Ideologie, falsches Bewußtsein yon einer nichts-sozialistischen Praxis ${ }^{66}(238)$

in dem Sinne ahistorisch, daß hier die Kritik der Theonie die Kritik der, wirklichen Bewegung", die immer Geschichte als Praxis ist, ersetzt.

Bei dieser Auffassung von Geschichte ist es dann allerdings nicht mehr möglich, die ,wirkliche Bewegung "tatsächlich zu explizieren.

„2... in den Regionen der Staatswirtschaft waren ganz iz der Stule die Fundamente eines breit ausladenden Staatskapitalismus entstanden." (239)

„Die Massen wollten eigentlich den Kommunismus, aber das Experiment bog sich von selbst zum Staatskapitalismus um. ${ }^{\text {is }}(240)$

Wenn auch mittels eines anderen Begründungsmusters - das hier wesen tlich auf die Theorie-Formen der sozialistischen Transformation rekurriert (241), sich darin naürlich auch unterschiedliche praktische Intentionen der Kritiker manifestierten - so zeigt sich doch in der anarcho-syndikalistischen Variante ein analoges Ergebris wie in der sozialdemokratischen: die Negation der Geschichte als Praxis.

\subsubsection{Die mao-strukturalist ische Variante (Charles Bettelheim)}

Die dritte Variante (242) kann als mao-strukturalistische gekennzeichnet werden, da durch sie die beiden Momente benannt sind, die das methodische Begründungsmuster dieses Nachweises der Existenz eines Staatskapitalismus bestimmen. Das

237) Zur Kritik einer deterministischen Interpretation des „phaseologischen Schemas von Marx" vgl. auch Helmut Fleischer, Marxismus und Geschichte, Frankfurt 1969, S. 40 ff, S. $77 \mathrm{ff}$.

238) Mattick, Marx und Keynes, a. a. O., S. 316

239) Steuermann (Pseudonym für Otto Rühle), a. a. O., S. 196

240) ebd., S. 229. Dieser spätere Text von Rühle (1931) enthält zahlreiche Widersprüche zu dem von 1924 (vgl. Anm. 236)

241) Die Frage der inhaltlichen Berechtigung der anarcho-syndikalistischen Kritik an der Leninschen Parteikonzeption bleibt hier unberücksichtigt. Um was es nur geht, ist zu zeigen, daß hỉ Theorie-Formen mit Praxisformen vollständig identifiziert werden, was eine Form der Ahistorizität impliziert. Zudem zeigt gerade die russische Entwicklung unmitelbar nach 1917, daß die ,wirkliche Bewegung ${ }^{66}$ nicht nur der stumme Exekutor der Leninschen Parteitheoric war, sondern vielfältige und wechsehde organisatorische Formen hervorgebracht hat. Vgl. dazu etwa Falk Döring, Organisationsprobleme der russischen Wirtschaft in Revolution und Bürgerkrieg (1918-1920), Dissertation Marburg/Lahn 1969; Walter Pietsch, Revolution und Staat, Dissertation Freiburg i. Br. 1968

242) Zwei weitere Varianten, die die hier angesprochene Problematik von Theorie und Geschichte in eklatanter Weise enthalten, können hier nicht mehr ausgefürt werden. Die cine (Cliff, Kidron u. a.) begrundet die Existenz eines Staatskapitalismus etwa in der Sowjecunion wesentlich aus der Existenz eines kapitalistischen Weltmarktes bzw. dem 
,mao" meint nicht die ,Freundschaft mit der VR China", sondern die methodische Implikation dieser ,Freundschaft" in der Theorie Bettelheims:

„Ich glaube, daß hier wieder die Kulturrevolution wesentlicher Gegenstand der theoretischen Reflexion sein muß. Wir haben die ungemein reichhaltige sowjetische Erfahrung, die es eines Tages noch ganz spezifisch zu analysieren gilt. Das ist bislang noch nicht vollständig durchgeführt, weil uns sowohl eine Reihe von Kategorien als auch die Exfahrung einer anderes gearteten Praxis fehlten." (243)

Diese ,anders geartete Praxis“ der chinesischen Kulturrevolution (244) wird allerdings dann zur programmatischen Norm erhöht, wenn sie jene ,Realinstanz ${ }^{66}$ (245) verkörpert, von der aus die moralisierende Frage gestellt wird, ,ob die Sowjetunion sozialistisch ist ${ }^{6 /}(246)$. Im Verfahren dieser komparativen Statik kann zwar die sowjetische Entwicklung qualifiziert, aber nicht mehr auf Basis ihrer eigenen konkreten Bedingungen begründet werden.

Das ,strukturalistische" Moment der Bettelheimschen Theorievariante aber ist wichtiger, da sich hierin ein Umschlag in der Theorie des Statskapitalismus (und der Theorie der Übergangsgesellschaft generell) manifestiert: ein Umschlag - wie einleitend formuliert wurde - vom Dilemma in der Erfassung der gesellschaftlichen Wirklichkeit der Übergangsgesellschaften zur Objektivierung dieses Dilemmas als Methode (247). (Hier kann allerdings nur auf einige Implikationen der strukturali-

Handel der Sowjetunion mit kapitalistischen Ländern. Es ist jedoch evident, daß von einer "Restauration des Kapitalismus" nur gesprochen werden kann, wenn eine Veränderung der Produkitonsverhältmisse in der Sowjetunion vorliegt.

Eine zweite Variante kann als ,bürgerliche“ Variante bezeichnet werden, da hier ein Kapital-Begriff zugrunde liegt, der "Kapital" nur in seiner dinghaften Gestalt, nicht aber als gesellschaftliches Verhältnis begreift. Vgl. etwa Witalij Grünstein, Staatskapitalismus und innere Handelspolitik der Union der sozialistischen Sowjetrepubliken, Dissertation Heidelberg 1928; oder Savel Zimand, State Capitalism in Russia, published by the Research Department of the Foreign Policy Association, New York 1926.

243) Charles Betteiheim, China und die Sowjetunion: Zwei ,Modelle" der Industrialisierung, in: Varga, Bet telheim,Maccio, Sowjetunion und China. Zwei Wege des sozialistischen Aufbaus, München 1970, S. 53

244) Wobei zu Bettelheim anzumerken wäre, daß er bis heute lediglich die Anfangsphase der Kulturrevolution theoretisiert. Auf Bettelheims jüngstes Elaborat und seine "Abrechnung" mit der sog. „Ultra-Linken" (Révolution culturelle et organisation industrielle en Chine, Paris 1973) wird in einem späteren Text noch eingegangen.

245) „Die doppelte Erscheinungsweise dieses normativistischen Verhältnisses zur, wirklichen Bewegung" besteht darin, daß a) die programmatische Norm jener wirklichen Bewegung...gegenüber in einer abstrakten, doktrinären Weise geltend gemacht wird, namentlich dort, wo man einen Verstoß gegen die Norm bemerkt, und b) daß man auf der anderen Seite eine geschichtliche Realinstanz (im Gegenwärtigen oder im Vergangenen) herauspräpariert, die integral als die Verkörperung des programmatisch Normierten ge!ten soll." (Helmut Fleischer, Methodologische Vorïberlegungen zum Begreifen revolutionärer Praxis - Zur Kritik des programmatischen Normativismus, in: Permanente Revolution, Nr. 1/2, a. a. O., S. 40)

246) Bettelheim, Ökonomischer Kalkül ..., a. a. O., \$. 7

247) Man kann natülich nicht sagen, daß dieser Umschlag ein bewußt vollzogener ist, da die Methode der strukturalen politischen Ökonomie ja nicht nur auf die Analyse der Transformationsperiode angewandt wird. In der Entwicklung der Theorie des Staatskapitalismus aber stellt sie objektiv einen solchen Wendepunkt dar. 
stischen Methode aufmerksam gemacht werden, soweit sie für die Problematik von Theorie und Geschichte in der Bettelheimschen Theorie des Staatskapitalismus relevant sind.) (248)

Die strukturale politische ökonomie geht von der Fragestellung aus: „Was ist der theoretische Gegenstand des Kapitals? ", verwirft die ,ökonomistische" und

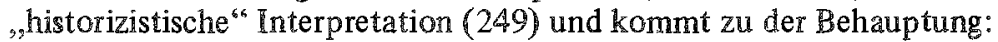

„Der theoretische Gegenstand bei Marx ist die kapitalistische Produktionsweise in ihrer Kerngestalt und die Determination dieser Kerngestalt. D. h., daß Marx nicht z. B. das kapitalistische England studiert, das er oft zur Illustration gebraucht, sondern er studiert in der begrifflichen Abstraktion als Erkenntnisobjekt einen ideellen Gegenstand." (250)

Der Gegenstand der Kritik der politischen ökonomie ist also nicht die Geschichte, sondern "die theoretische Konstruktion des Objekts der Geschichte, das heißt ihr Begriff: Analyse der Transformationsperiode bedeutet demnach,

„den Begriff von Geschichte zu konstruieren, der den verschiedenen, so erreichten Strukturen entspricht." (251)

Eine entscheidende Konsequenz dieser methodischen Direktive zeigt sich etwa bei Bettelheim darin, daß er es ablehnt, von einem ,Überleben " der Warenkategorien in der Übergangsgesellschaft zu sprechen, stattdessen von ihrem „Vorhandensein " ausgeht. Was ist der Sinn dieser scheinbaren Spitzfindigkeit?

„... man erklärt die Gegenwart nicht mit einem simplen Verweis auf die Vergangenheit. Das Problem muß in sich untersucht werden." (252)

Die Warenverhältnisse in der Transformationsperiode sind nicht mehr die ,Muttermale der alten Gesellschaft" (253), sondern die Produkte der Strukturen (254) der Übergangsgesellschaft selbst, die nicht mehr als Negation des Kapitalismus er-

248) Zur detaillierten Kritik der Bettelheimschen Theorie vgl. K. Nair und Jean-Luc Dallemagne, beide in: Kritik der politischen Ökonomie Nr. 1, Westberlin 1973

249) Nicos Poulantzas, Theorie und Geschichte. Kurze Bemerkungen über den Gegenstand des "Kapitals", in: Kritik der politischen Ökonomie heute. 100 Jahre "Kapital", Frankfurt 1968, S. 58; Louis Althusser/Etienne Balibar, Das Kapital lesen, 2 Bände, Reinbek 1972, 5. 94 ff.

250) Charles Bettelheim, Problématique de l'économie de transition, in: Etudes de Planification Socialiste N. 3, Paris 1966, S. 127 f. Zur Unterscheidung von ,Erkenntnisobjekt ${ }^{66}$ und ,realen Objekten" vgl. Althusser/Balibar, a. a. 0 .

251) Poulantzas, a. a. O., S. 68. Die Bedeutung der Unterscheidung von Geschichte und „Begriff von Geschichte ${ }^{4}$ wird etwa darin sichtbar, was Althusser iber die Kategorie des Mehrwerts schreibt: „Daß der Mehrwert keine meßbare Größe ist, liegt daran, daß er keine Sache sondern der Begriff einer Beziehung, der Begriff einer gesellschaftlichen Produktionsstruktur ist ...". (Althusser/Balibar, a. a. O., S. 243)

252) Bettelheim, Ökonomischer Kalkül..., a. a. O., S. 15

253) Karl Marx, Kritik des Gothaer Programms, in: MEW 19, Berlin/DDR 1969, \$. 21

254) „Ce qui nous appellerons pour le moment des, survivances'... représente en fait, les produits des structures dans lesquels ces prétendues, impuretés' ne sont pas des, survivances', car elles ne sont pas étrangères aux structures réelles dans lesquelles elles se trouvent. ${ }^{66}$ (Bettellheim, Problématique ..., a. a. O., S. 130) 
scheint. In diesem Axiom einer Übergangggesellschaft , in sich $^{66}$, ist bereits Bettelheims gesamter Nachweis einer ,Restauration des Kapitalismus" angelegt. Er braucht die ,vorhandenen" Warenverhältnisse (d.h. die Zirkulation) nur noch als ,Zeichen" von ,Kapital, verwertung" "(d.h. der Produktion) zu setzen (255) und die ,Restauration des Kapitalismus" ist erklärt - ideologisch (256).

Aber durch welche Strukturen werden die ,vorhandenen "Warenverhältnisse produziert?

„Der kapitalistische Charakter des, Unternehmens ${ }^{6} \ldots$ besteht darin, daß seine Struktur die Gestalt einer doppelten Trennung annimmt: die Trennung der Arbeiter von ihren Produktionsmitteln ... und die Trennung der einzelnen Unternehmen untereinander. " (257)

Die "Struktur" des Unternehmens ist aber erst dann , ${ }_{g}$ kapitalistisch", wenn sie $\mathbb{R e}$ sultat eines gesellschaftlichen Verhältnisses ist, das dadurch gekennzeichnet ist, daß die Arbeitskraft Ware ist, daß folglich Lohnarbeit existiert etc. Die bloße ,Trennung $^{\text {"6 }}$ von unmittelbaren Produzenten und Leitern des Produktionsprozesses ist noch kein Indiz für kapitalistische Produktion. Diese ,Struktur" des Unternehmens ist nicht von Natur aus kapitalistisch (258).

Die "Trennung der einzeinen Unternehmen untereinander" bedeutet in der Konsequenz, daß Konkurrenzverhältnisse zwischen diesen Unternehmen existieren, folglich das Wertgesetz Regulator der gesellschaftlichen Produktion ist, etc. Für Bettelheim allerdings ist es ,unwichtig", ob diese Autonomie der Unternehmen „formal oder wirklich" (259) ist. Das ist eine der Folgen, wenn man statt Geschichte den ,Begriff" von Geschichte expliziert.

Nach diesem ,Nachweis" der Existenz von kapitalistischen Verhältnissen, formuliert Bettelheim eine „Erweiterung des Begriffs ,Staatskapitalismus“ “:

„,Der Begriff des ,Staatskapitalismus ${ }^{\circ}$ bezeichnet das in Bezug auf das Staatseigentum artikulierte System der kapitalistischen Produktionsverhältnisse" (260),

wobei zwei Modalitäten möglich sind: ,Staatskapitalismus unter der Diktatur des Proletariats“ (261), der zu einem ,Staatskapitalismus, der von einer Staatsbourgeoisie beherrscht wird" (262) transformiert werden kann, was letztendlich bedeutet, daß der politische Ưberbau dominierend bleibt. Das allerdings heißt, daß seit 1917 ein Staatskapitalismus existiert hat, die ,Restauration des Kapitalismus" im Grunde also nur eine Restauration der „Bourgeoisie ${ }^{66}$ ist, sie daher auch evolutionär erfolgen konnte.

Bei der Analyse dieser ,Restauration des Kapitalismus" abstrahiert Bettel-

255) Bettelheim, Ökonomischer Kalkül ..., a. 2. 0., S. 23, S. 52

256) Vgl. zur Kritik: Dallemagne, a. a. O., S. 30, S. 60

257) Betrelheim, Ökonomischer Kalkül ..., a. a. O., S. 72

258) Vgl. zur Kritik: Nair, a. a. O., S. 16 f.

259) Bettelheim, Ókonomischer Kalkül ..., a. a. O., S. 92

260) ebd., S. 81. Bettelheim wendet sich gegen den "deskriptiven Charakser" des Staatskapitalismus-Begriffs bei Lenin (ebd., S. 162)

261) ebd., S. 82

262) ebd., S. 93. Bettelheim scheint sich noch nicht ganz schlüssig darïber zu sein, ob diese "Staatsbourgeoisie" eine "Gesellschaftsschicht" oder ,Klasse" repräsentiert (ebd., \$. 90) 
heim bewußt ,von der Analyse der konkreten Bewegung der Klassenkämp$\mathrm{fe}^{\text {" }}$ (263), dern Geschichte ist für ihn Geschichte ohne Subjekte. Diesen zweiten, ,anti-humanistischen" Aspekt der strukturalen politischen Ökonomie hat Althusser begnindet:

,Die wahren (einen Prozeß konstituierenden) ,Subjekte" sind... eben nicht die ,konkreten Individuen ${ }^{6}$ und die, wirklichen Menschen"; die wahren ,Subjekte ${ }^{6}$ sind ... die Produktionsverhältrisse..." (264)

Die „Struktur" erhält so ihre eigene Kausalität: sie ist Geschichte; die „kapitalistische Struktur ${ }^{\text {66 }}$ der Unternehmen ist die Restauration des Kapitalismus.

Zwei Momente kennzeichnen demnach das Verhältnis von Theorie und Geschichte in der strukturalen politischen ökonomie. Wenn der Gegenstand der Theorie nicht die Geschichte ist, sondern der konstruierte „Begriff“ von Geschichte, verlagert sich die theoretische Analyse, , $y$ on der Wirklichkeit zur Theorie der Wirklichkeit" (265). Die Folge dieser Verlagerung ist, daß sich dann Theorie, in sich ${ }^{66}$ legitimiert, ,Begriffe" außerhalb einer Aneignung des Konkreten produziert werden können (266) und die ,wirkliche Bewegung" beliebig subsumierbar wird.

Wenn andererseits, Strukturen" die, wahren Subjekte" der Geschichte sind, wird Geschichte als Dimension der Praxis liquidiert. Was übrig bleibt ist die ,programmatische Norm", von der man allerdings nicht mehr angeben kann, wie sie $\mathrm{zu}$ pealisieren ist (267).

\section{Schluf folgerungeil}

Mit der Skizzierung der mao-strukturalistischen Variante ist der Ausgangspunkt dieser Arbeit wieder erreicht: das ,Dilemma" in der theoretischen Analyse der Ubergangsgesellschaften durch die sozialistische Bewegung in den noch kapitalistischen Ländern. Dieses, „Dilemma ${ }^{66}$ hat aber jetzt einen konkreteren Inhalt, der einige Schlußfolgerungen zuläßt.

1. Die Schwierigkeit einer materialistischen Analyse der Transformationsprozesse existiert nicht erst seit den aktuellen Zersetzungserscheinungen einer

263) Bettelheim, Remarques théoriques..., zitiert bei: Dallemagne, a. a. O., S. 44. Schon während der sog. cubanischen Planungsdebatte hat Che den Theoretiker Bettelheim ermahnt: "...daß eine wirtschaftliche Analyse nie von der historischen Tatsache des Klassenkampfs gelöst werden kann." (Ernesto Che Guevara, Die sozialistische Planung und ihre Bedeutung, in: Bettelheim/Castro/Guevara ..., a.a. O., S. 152)

264) Althusser/Balibar, a. a. O., S. 242

265) Diesen Aspekt in der Kritik des Strukturalismus hat André Glucksmann, A Ventriloquist Structuralism, in: New Left Review Nr. 72, London 1972, betont.

266) Bettelheim, Ökonomischer Kalkül ..., a. a. O., S. 7

267) Dieser doppelte Aspekt der Bettelheimschen Theorie, sein programmatischer Normativismus und seine Konstruktion einer Theorie ,in sich“, erklären, daß Bettelheim sowohl zum potentiellen Wortführer einer theoretizistischen wie einer sich als Partei kostümierenden Fraktion der Intellektuellenbewegung werden konnte: zum Theoretiker zweier unterschiedlicher Formen von Enthistorisierung und Entpolitisierung marxistischer Theorie. 
Intellektuellenbewegung und besteht nicht bloß in einer mangelnden Vermittlung von Theorie und Empirie. Es ist daher aringend notwendig, von der blob beschränkten Kritik dieser aktallen Erscheinungsformen zu einer radikaleren Kritik uberzugehen: zur Kritik der Kategorien und der Methode. Allerdings kann es sich nicht darum handeln, ,falschen" Kategorien und einer ,falschen" Methode das jeweilig, Richtige" entgegenzustellen. Es muß zugleich gezeigt werden, unter welchen Bedingungen überhaupt entsprechende Kategorien produziert werden können. Hierfür lassen sich aus der - wenn auch fragmentarischen - Rekonstruktion der Theorie des Staatskapitalismus Kriterien entwickein.

2. Am Beispiel der Theorie des Staatskapitalismus konnte gezeigt werden, wie diese unter bestimmten historischen Bedingungen als ideologische TheorieForm kapitalistischer Entwicklung entsteht und in der russischen Revolution als theore tischer Ausdruck des Transformationsprozesses dient. Aus historisch erklärbaren Umständen wird sie durch die Revolutionäre selbst auf die Übergangsgesellschaft übertragen.

3. Durch die Erfahrung der realen Praxis der Transformation in Rußland erhält der Begriff des Staatskapitalismus jedoch einen in der Vergesellschaftung der Arbeit zwischen kapitalistischer Metropole und ökonomisch rückständigem Land sigualisiert, $z u$ einem Begriff, der positiv die Tendenz der Transformation auf der Basis der konkreten Bedingungen im ökonomisch rückständigen Land formuliert. Die reale Praxis revolutionierte die Begriffe.

4. Diese praktische Korrektur ideologischer und ubertragener Kategorien setzte voraus, daß diese Praxis selbst Handlungsvarianten kannte, die ihrerseits Öffentlichkeit (268) und Benennung von Schwierigkeiten (269) implizierte, andererseits die Begriffe selbst als transitorische gedacht wurden (270).

5. Demgegenüber ist die damalige sozialdemokratische und anarcho-syndikalistische Kritik dadurch gekennzeichnet, daß sie eine sich entwickelnde Realität an verdinglichten Kategorien (, ,objektive Verhältnisse") mißt bzw. die Theorie-Formen der geschichtlichen Subjekte mit deren realer Praxis identifiziert. In beiden Fällen verschwindet das Kriterium der Praxis aus der Geschichte (obwohl beide Varianten ihre historische Singularität haben).

6. Diese Liquidierung der praktischen Dimension von Geschichte ist nicht zufällig. Sie ist Ausdruck der Tatsache, daß den Kritikem die unmittelbare Erfah-

268) „Den Massen verheimlichen, daf die Heranziehung burgerlicher Spezialisten durch außerordentlich hohe Gehälter eine Abweichung von den Prinzipien der Kommune ist, würde bedeuten, auf das Niveau birgerlicher Polikikaster hinabsinken und die Massen betrügen. Offen erklären, wie und warum wir den Schritt zurick gemacht haben, dann offentlich beraten, welche Mirtel vorhanden sind, das Versäumte nachzuholen - das bedeutet die Massen exzehen und zusammen mit ihnen aus der Erfahrung lernen, wie man den \$ozidlismus aufbauen muß" "Lenin, Die nächsten Aufgaben ..., a, a. $0 ., 5.744 \mathrm{f}$.

269) Vgl. etwa das Kapitel "Uber die Methode der theoretischen Analyse der sowjetischen Wirtschaf " bei Preobrazenskij, Neue Ökonomik, a. a. O., S. 55-97

270) ,Wenn die Wissenschaft überhaupt in ihrem jetzigen Zustand fließende ,Prozesse und nicht erstarte, metaphysische ,Wesenheiten' erforscht, so werden gerade in der Ubergangsperiode aus offensichtlichen Gründen die Kategorien des Seins durch Kategorien des Werdens ersetzt. "Bucharin, Ökonomik . ., a. a. O., \$. 132 
rung einer Praxisform des Übergangs fehlt. Oder anders: ihre theoretischen Konzepte sind das Produkt ihrer eigenen gesellschaftlichen Bedingtheit, Theorie-Formen der kapitalistischen Gesellschaft.

7. Ihr ,Staatskapitalismus ${ }^{66}$-Begriff verdeckt daher die realen Widerspruiche des Ubergangs, anstatt sie - wenn auch in einer ideologischen Theorie-Form - zu enthïllen. Die ,wirkliche Bewegung " besteht für sie im Schwanken zwischen Zusammenbruchs-Hypothese und Apologie.

8. Dieses Dilemma, Theorieproduktion außerhalb einer geschichtlichen Praxis (von der sich erst eine bestimmte methodische Verfahrensweise und die Vermittlung Theorie/Empirie begründet) schlägt heute in einen Objektivismus um, der explizit die Geschichte ausklammert und so das eigentliche Problem verdeckt.

9. Dieser Objektivismus ist micht verifizierbar, er begründet sich selbst. Er wird Klassenverhältnisse qua eines „Vorhandenseins" bestimmter „Strukturen" postulieren, nicht aber begrüinden können.

10. Die Frage nach dem "Klassencharakter der revisionistischen Staaten " wird durch die westliche sozialistische Bewegung zwar gestellt, nicht aber gelöst werden können. Die Klassenanalyse würde zur bloß kategorialen und funktionellen Differenzierung verkommen, die von Analogien zur eigenen Geschichte lebt.

11. Die theoretischen Analysen der Transformationsprozesse werden erst dann wieder Theorie und Geschichte reintegrieren, wenn sie ,in den Gebieten selbst von marxistischen Revolutionären durchgeführt werden, die aktiv an der Bewegung teilnehmen, der die Analyse dienen soll." (271)

Das Konzept einer Reintegration von Theorie und Geschichte ist so mehr als bloße methodische Finesse; es impliziert vielmehr die Aufhebung des sich äußerlichen Verhältnisses von Objekt der Theorie und theoretisierendem Subjekt, die die praktische Revolutionierung der Theore tiker einschließt.

Mai 1973

271) André Gunder Frank, Lateinamerika: Kapitalistische Unterentwicklung oder sozialistische Revolution, in: Kritik des bürgerlichen Anti-Imperialismus ..., a. a. O., S. 124. Ich bringe bewußt diese Analogie zu den unterentwickelten Ländern, weil sich hier der Ablösungsprozeß einer Unterentwicklungs-Theorie aus den Metropolen durch eine Theorie aus jenen Ländern selbst insb. nach der cubanischen Revolution exemplarisch zeigt. 